\title{
TASK TRADE BETWEEN SIMILAR COUNTRIES
}

\author{
By Gene M. GRossman AND EstebAN Rossi-HANSBERG ${ }^{1}$
}

\begin{abstract}
We propose a theory of task trade between countries that have similar relative factor endowments and technological capabilities, but may differ in size. Firms produce differentiated goods by performing a continuum of tasks, each of which generates local spillovers. Tasks can be performed at home or abroad, but offshoring entails costs that vary by task. In equilibrium, the tasks with the highest offshoring costs may not be traded. Among the remainder, those with the relatively higher offshoring costs are performed in the country that has the higher wage and the higher aggregate output. We discuss the relationship between equilibrium wages, equilibrium outputs, and relative country size.
\end{abstract} tion.

KEYWORDS: Fragmentation, offshoring, outsourcing, production chains, globaliza-

\section{INTRODUCTION}

MODERN PRODUCTION assigns a prominent role to international task trade. The delivery of a good or service to a consumer typically requires the completion of a myriad of tasks. Increasingly, the performance of these tasks is spread across the globe, with an impressive share of offshore production in the value of many final goods. As a result, international trade is less today a matter of countries' specialization in particular industries and more about their specialization in particular occupations and tasks.

Much has been written about the growth of offshoring between countries that stand at different levels of development, that is, countries that have dissimilar factor endowments and disparate technological capabilities. ${ }^{2}$ Yet, as important as this sort of offshoring is becoming in world trade, it pales in comparison to task trade between countries that are similar in terms of these characteristics. Although aggregate data on offshoring from one developed country to others are difficult to come by, we do know that most trade in intermediate goods takes place between and among the advanced industrialized economies, and that most value added generated by foreign subsidiaries of

\footnotetext{
${ }^{1}$ We thank Aykut Ahlatçığlu and Shlomi Kramer for research assistance, Daron Acemoglu, Sebastian Benz, Philipp Ehrl, Gordon Hanson, Giovanni Maggi, Marc Melitz, Jens Wrona, and Kei-Mu Yi for discussions and comments, and the National Science Foundation (under Grants SES 0211748 and SES 0451712) and the Sloan Foundation for research support. This paper was completed while Grossman was a Visiting Research Fellow in the Development Economics Vice Presidency at the World Bank. He thanks the World Bank for support and the Trade and Integration Team (DECTI) for its hospitality. Any opinions, findings, and conclusions or recommendations expressed in this paper are those of the authors and do not necessarily reflect the views of the National Science Foundation, the World Bank Group, or any other organization.

${ }^{2}$ See, for example, Jones and Kierzkowski (2001), Feenstra and Hanson (1996), Deardorff (2001), Yi (2003), Egger and Falkinger (2003), Kohler (2004a, 2004b), and Baldwin and RobertNicoud (2010), as well as our own work in Grossman and Rossi-Hansberg (2008).
} 
American multinational corporations originates in other Organization for Economic Cooperation and Development (OECD) countries. ${ }^{3}$ Both facts suggest that the advanced economies are engaged in a substantial amount of international production sharing with others at similar levels of development.

Not only does most trade flow between and among the advanced industrialized economies, but these economies are engaging in an ever more intricate web of production-sharing arrangements. The Boeing 787 Dreamliner is a case in point. ${ }^{4}$ The production of this new midsize jet involves 43 suppliers spread over 135 sites around the world. Boeing relies heavily on local expertise when making its sourcing decisions. The wings are produced in Japan, the engines in the United Kingdom and the United States, the flaps and ailerons in Canada and Australia, the fuselage in Japan, Italy, and the United States, the horizontal stabilizers in Italy, the landing gear in France, and the doors in Sweden and France. Offshore production accounts for close to 70 percent of the many thousands of parts used to assemble the jet (Newhouse (2007, p. 29)). Some parts are produced in foreign affiliates of the Boeing Corporation, while others are supplied under international outsourcing agreements. The countries that perform the various tasks display no clear pattern of technological advantage. Rather, experience and local knowledge play a central role. Apparently, expertise most often derives from similar tasks being performed for other Boeing projects or for related industries, such as military aviation and automobile production. $^{5}$

In this paper, we formulate a theory of task trade between countries that have similar exogenous sources of comparative advantage but differ in size. In our model, the supply of any good requires a fixed input of managerial effort plus the completion of a continuum of production tasks. The set of required tasks is the same for all goods, yet the resulting products are differentiated in the eyes of consumers. Producers of the final goods engage in monopolistic competition and sell their wares to consumers who hold constant elasticity of substitution (CES) preferences. We explore the links between country size and the pattern of specialization and task trade.

\footnotetext{
${ }^{3}$ Many researchers have documented production sharing for particular countries in their trade with the rest of the world; see, for example, Campa and Goldberg (1997), Hummels, Rapoport, and Yi (1998), Hummels, Ishii, and Yi (2001), and Hanson, Mataloni, and Slaughter (2005). Among these, only Hummels, Ishii, and Yi (2001) went on to consider the geographic nature of the production-sharing relationships. They found that North-North specialization is the most common form of vertical specialization in world trade. The data reported in World Trade Organization and IDE-JETRO (2011, p. 84) show that intra-European and European-North American trade accounts for a large share of trade in intermediate goods. The data in Barefoot and Mataloni (2010) reveal that nonbank multinational subsidiaries of American parent companies hold a large fraction of their assets in other developed countries and generate a large share of their offshore value added there.

${ }^{4}$ The sourcing of Boeing's parts for the 787 is detailed at http://www.boeing.com/commercial/ 787family/background.html. See Newhouse (2007) for further discussion.

${ }^{5}$ See "A Cleverer Way to Build a Boeing," The Financial Times, July 8, 2007.
} 
The Boeing Dreamliner example can help us to contrast our notion of a "task" with the commonly used concept of an intermediate good. In our formulation, a task is the finest possible addition to the value added of a good or service done by a particular factor of production. Of course, actual international trade transactions in general involve bundles of tasks that fit the description of an intermediate good. Thus, a theory of task trade can be understood as a theory in which the characteristics of the bundles of tasks forming intermediate goods are determined endogenously depending on the cost of offshoring each task. The "wings" of the Dreamliner may be produced in Japan, but the particular composition of the wing-whether it includes assembly, testing, and painting, for example-is not technologically predetermined, but rather is part of the deliberate production design by Boeing.

In keeping with the anecdotal evidence cited above, our treatment of production sharing emphasizes the role of local knowledge and specialized expertise. Our approach shares with the "new trade theory" a focus on increasing returns to scale as a force that induces concentration of production. But whereas the most familiar models in that literature feature trade in final goods-for which scale economies internal to the firm may be most pertinent-our focus on task trade dictates a different approach. The expertise to produce a unique good may well reside in a single firm, but the expertise to perform a narrow task rarely does so. Rather, it is often embodied in a pool of specialized labor, be they engineers with specific training or workers with shared experience. This suggests that, in the absence of complete contracts, localized knowledge at the task level may reflect external economies of scale rather than (or in addition to) internal economies. We take this notion to the extreme by assuming that productivity in performing a task varies with the frequency with which it is performed in a particular location, irrespective of the identity of the firm or firms performing the function.

The location of each task balances two competing forces. On the one hand, the external economies of scale provide firms with an incentive to locate each task in the country where others are performing it. On the other hand, it is costly for firms to organize and monitor the performance of tasks in countries different from where their headquarters are located. Our model features heterogeneous offshoring costs to capture the reality that some tasks are easier to separate from firms' headquarters than others. For example, routine tasks can be performed remotely at relatively little extra cost, because instructions can be expressed unambiguously and conveyed easily to workers, with little need for interaction with central management. Other tasks may require greater adaptation to circumstances, so proximity to headquarters may be more important. ${ }^{6}$

\footnotetext{
${ }^{6}$ Autor, Levy, and Murnane (2003) emphasized this distinction between routine and nonroutine tasks, and provided a measure of this concept. Levy and Murnane (2004) and Grossman and Rossi-Hansberg (2008) applied the concept to explain variation in the costs of offshoring.
} 
Our analysis links the pattern of specialization by task to the distribution of offshoring costs.

When small firms operate in an environment with external economies of scale, they face an obvious coordination problem. If other firms are performing an activity in some location, it may be most profitable to join them there, even if all other economic forces point to a different outcome. As a result of the potential coordination failures, multiple equilibria can arise. Multiplicity of equilibrium has plagued models with production externalities, where "history" and "expectations" play a role in determining final outcomes. With a continuum of tasks and the possibility for self-fulfilling expectations for each of them, it might appear that little could be said about the equilibrium allocation of tasks across countries. Yet the environment with many tasks suggests a solution to the coordination problem that narrows the set of equilibria dramatically. In particular, we recognize that firms can perform tasks on behalf of others. The opportunity for a firm to perform a task for many producers means that it potentially can internalize the externalities of locational choice. Such a supplier need not be large in relation to its industry, because even if it dominates the performance of a particular task, there are many other tasks to be done. By introducing the possibility for outsourcing tasks, we can cut through the coordination issues and say quite a lot about the pattern of specialization in equilibrium. ${ }^{7}$ Our approach then suggests that in the presence of local externalities and global trade, the scope for multiplicity will be narrowed by outsourcing, because it allows agents to profit from any coordination failures that might otherwise arise.

Our main proposition relates the pattern of specialization by task to equilibrium relative wages and equilibrium aggregate outputs. It states that all firms perform the tasks that are most costly to offshore in the country of their headquarters. Among the remaining tasks, those that are easiest to offshore concentrate in the country that has lower wages and lesser aggregate output, while those that are more difficult to offshore concentrate in the country that has higher wages and greater aggregate output. Depending on the overall level of offshoring costs, the general equilibrium may be unique or not. With offshoring costs sufficiently high that identical-sized countries would engage in no production sharing, the unique equilibrium with unequal-sized countries has higher wages in the larger country. When offshoring costs are not so high, there will be multiple equilibria in a world with countries of nearly identical size, but a unique equilibrium when country sizes diverge. In the former case, there is one equilibrium in which wages are higher in the (slightly) larger country, another in which wages are higher in the (slightly) smaller country, and a third equilibrium with equal wages. In the latter case, the (much) larger country enjoys the higher wages.

\footnotetext{
${ }^{7}$ As we argued in Grossman and Rossi-Hansberg (2010), a similar set of assumptions can also be used in a context with only final goods to eliminate equilibrium multiplicity.
} 
We are not aware of other efforts to explain the pattern of task trade between similar countries in the nascent literature on offshoring. Markusen and Melvin (1981) and Ethier (1982) were the first researchers to explore the determinants of the trade pattern in general-equilibrium settings with Marshallian production externalities. ${ }^{8}$ Although their results are superficially similar to ours, the underlying economics are quite different. In their models, stability (and efficiency) dictates concentration of the increasing-returns industry in a single country. The smaller country may lack sufficient resources to satisfy world demand for this good, even if it is completely specialized, whereas the larger country always can do so. ${ }^{9}$ In our context of task trade, the ability to accommodate world demand never is at issue, because any small task can easily be concentrated in either location. The pattern of specialization does not rest on country size per se, but rather on the interplay between the scale of aggregate production of final goods and the offshoring costs.

Our results resemble some in the literature on market-size effects. ${ }^{10}$ In both cases, locational advantages give rise to factor-price differences, as the country that bears higher transport costs must offset this disadvantage so that its factors are fully employed. In the literature on the home-market effect, scale economies are internal to the firm and cost differences stem solely from market size. In contrast, external economies of scale seem more pertinent for modeling production sharing. The recognition of such externalities requires us to address coordination issues and the role of producers who potentially can internalize these benefits. Also, for task trade, the scale of final-goods production and not the location of final demand determines the pattern of specialization. The country that produces more final goods need not be the one with the greater factor endowments.

The remainder of this paper is organized as follows. In Section 2, we develop our model of offshoring, discuss the equilibrium allocation of tasks given factor prices and aggregate outputs, and lay out the conditions for a general equilibrium. Section 3 studies the general equilibrium of the model and discusses uniqueness of equilibrium and other equilibrium properties. The section proceeds to a discussion of the relationship between country size, aggregate output of final goods, and relative wages, and presents our main result on the pattern of specialization. Section 4 concludes.

\footnotetext{
${ }^{8}$ See, also, Melvin (1969) for an early contribution and Helpman (1984) for a survey and further discussion.

${ }^{9}$ In Grossman and Rossi-Hansberg (2010), we studied a trade model with Marshallian externalities in a continuum of final-goods industries. In such a setting, country size plays no role in determining the chain of comparative advantage. It does, however, affect the cutoff between goods that are produced in each country.

${ }^{10}$ See Krugman (1980) for an early contribution and Hanson and Xiang (2004) for a study of market-size effects in an economy with many industries and heterogeneous transport costs.
} 


\section{THE MODEL}

Production requires many "tasks." Each task can be performed close to a firm's national headquarters or at a foreign location. If a task is performed offshore, the firm bears an extra cost of coordinating production and communicating with distant workers. The cost of offshoring varies by task. Some tasks require more frequent and intense interaction between workers and managers, while others are easier to perform from a distance.

We study an environment with external economies at the task level. A firm's productivity in performing a task in a particular location increases with the total scale of performance of the task by all firms in that same location. As in the literature on increasing returns to scale at the industry level, the external economies are meant to capture the presence of localized knowledge spillovers. $^{11}$

There are two countries, East and West. Each country is endowed with fixed supplies of two primary factors: managers and workers. In East, the supplies of these factors are $H$ and $L$, respectively; in West, they are $H^{*}$ and $L^{*}$. The similarity of the two countries is reflected in their identical relative factor supplies and identical technological capabilities. Although $H / L=H^{*} / L^{*}$, the sizes of the two countries typically will not be the same.

A producer must perform (or procure) a unit measure of tasks to generate final output. The set of tasks that are performed by different producers is the same, but their resulting outputs are differentiated in the eyes of consumers. Let $\sigma>1$ be the elasticity of substitution between any pair of final products. The world market for these consumption goods is characterized by monopolistic competition, with (constant) markup pricing and zero profits. We abstract from any cost of transporting final goods so as to highlight the costliness of offshoring.

The tasks that comprise a firm's variable cost are performed by workers alone. A firm can perform a task locally or offshore, and it can do so either in-house or by outsourcing the task to another firm. Before incurring any production (or procurement) costs, each firm must hire managers to oversee production and coordinate the performance of the various tasks. A firm requires $f$ managers in the country of its headquarters as a fixed cost of doing business.

We model the siting of each task as a two-stage game. After a set of firms has borne the fixed cost of entry, market participants engage in a location and pricing stage, when each firm locates its productive capacity for each task $i$ and posts a set of prices at which it is willing to perform the task for others. Since the tasks are performed on behalf of particular final producers, we allow for price discrimination; that is, a firm may quote one price to perform the task

\footnotetext{
${ }^{11}$ On this point, see, for example, the discussions in Marshall (1920), Helpman (1984), Romer (1986), and Lucas (2002), among many others.
} 
on behalf of other firms headquartered in East and a different price to perform the task for firms headquartered in West. ${ }^{12}$ These price quotes include any offshoring costs (which are described further below). In the subsequent production stage, each firm decides whether to perform each task in house, to perform each task in the location that it previously selected, or to contract for the task under an outsourcing arrangement. The make-or-buy decisions are made simultaneously by all producers. We confine attention to subgame perfect equilibria of this two-stage game.

There are external economies in the performance of every task. These economies generate national increasing returns to scale. Suppose that task $i$ is performed a total of $X_{i j}$ times in some country $j$. Then a firm that has its headquarters in country $j$ and that chooses country $j$ as its location for task $i$ can perform the task in-house with $1 / A\left(X_{i j}\right)$ workers per unit of output, where $A(\cdot)$ is positive, increasing, and concave, and $\lim _{X \rightarrow \infty} A^{\prime}(X)=0$. The labor requirement is the same when a firm performs the task for itself or on behalf of another. If a firm performs task $i$ in country $j$ for a producer (itself or another) with headquarters in country $j^{\prime} \neq j$, then it bears the higher per unit labor requirement $\beta t(i) / A\left(X_{i j}\right)$. Here, $\beta t(i)>1$ reflects the cost of offshoring task $i$.

Our modeling of offshoring costs mirrors that in Grossman and RossiHansberg (2008). The schedule $t(i)$ captures the heterogeneity of these costs across tasks. We index tasks so that $t^{\prime}(i)>0$. Tasks with low indexes are those for which instructions can be communicated internationally with little loss of information. In contrast, remote performance of tasks with high indexes is problematic, because these tasks must be monitored closely by headquarters and require intensive interaction between managers and workers. The parameter $\beta$ is a technological parameter that reflects the state of communications technology and other technological conditions that determine the ease of coordinating economic activities across countries.

The outcomes of the location and production games for all of the tasks give each firm its per-unit cost of final output. Firms mark up their costs to maximize profits. The general equilibrium determines the measure of producers in each country, the outputs and prices of all varieties of the final good, and the factor prices in each country.

In the remainder of this section, we analyze the siting of each task $i \in[0,1]$, taking the numbers of differentiated products, the aggregate output levels, and the factor prices in each country as given. In Section 2.3, we link the quantities and prices to the locations of the various tasks, thereby completing the conditions for a general equilibrium.

\footnotetext{
${ }^{12}$ It could quote a richer set of prices, but since the firms headquartered in a given location are symmetric, it has no reason to do so.
} 


\subsection{Location of Tasks}

Suppose there are $n$ firms headquartered in East and $n^{*}$ firms headquartered in West. All firms generate their output by performing or procuring a continuum of tasks. We focus on some particular task $i$ and ask where the firms locate their capacities for performing this task and whether they ultimately perform it for themselves or engage in outsourcing. In addressing the siting of capacities for a particular task $i$ and the associated make-or-buy decisions, we take the per-firm output levels $x$ and $x^{*}$ and the wage rates $w$ and $w^{*}$ in East and West, respectively, as given. If the $n$ Eastern firms each produce $x$ units of final output, then task $i$ must be performed a total of $n x$ times by these firms or by others on their behalf. Similarly, task $i$ must be performed $n^{*} x^{*}$ times by or on behalf of the Western producers. Following the discussion above, we define a location equilibrium for task $i$ as follows.

DEFINITION 1: Given $n, n^{*}, x, x^{*}, w$, and $w^{*}$, a location equilibrium for task $i$ is a set of firm-specific capacity location choices (East or West) and price pairs (price for Eastern firms and price for Western firms) in the first stage, and a set of procurement choices (self-procure or buy from a particular seller) in the second stage, such that these strategies constitute a subgame perfect Nash equilibrium of the two-stage game.

Definition 1 rules out, of course, any placements of task $i$ or any subsequent procurement decisions that allow for a profitable deviation by some firm. To characterize the location equilibrium for all of the tasks in the unit interval, we first derive a trio of thresholds that identify the sets of tasks that are immune to certain types of deviations. Then, in Proposition 1 below, we use these thresholds to characterize a location equilibrium for each task $i \in[0,1]$.

We will see that the pricing competition is standard and familiar from Bertrand models. The novel element here concerns the capacity location choices. In general, a prospective equilibrium with all firms placing their capacities for task $i$ in some location is susceptible to two types of deviations. First, some firm might locate in the opposite country and price in such a way as to attract as customers all firms (and only firms) that have their headquarters there. We refer to this strategy as a local deviation inasmuch as the deviant pursues only local sales in the country where it locates. Second, a deviant might locate its capacity for task $i$ in the opposite location and price in such a way as to attract all firms worldwide as outsourcing customers. We refer to this strategy as a global deviation. For any conceivable location equilibrium with concentrated placement of task $i$, we must check that neither a local deviation nor a global deviation is profitable. If a task cannot be concentrated in East or in West-due to the existence of profitable deviation opportunities of some sort - then we must entertain the possibility that Eastern firms locate their capacity for that task in East and Western firms do so in West. Again, we allow 
for alternative pricing strategies that involve competing for (only) local sales and competing for global sales.

Let us explore first the possibility that all firms locate their capacity to perform task $i$ in East. If each firm expects the others to locate similarly, Bertrand competition leads them to price at expected cost. Let $p_{i}^{j}$ be the price posted by a typical firm for performing task $i$ for another firm that is headquartered in location $j$. Then our conjectured equilibrium prices for task $i$ are

$$
p_{i}^{E}=\frac{w}{A\left(n x+n^{*} x^{*}\right)} \quad \text { and } \quad p_{i}^{W}=\frac{w \beta t(i)}{A\left(n x+n^{*} x^{*}\right)}
$$

where $w$ is the wage in East, $x$ is final output of a typical Eastern producer, and symbols with asterisks are the corresponding variables for West. Note that if task $i$ is concentrated in East, it will be performed there a total number of $n x+n^{*} x^{*}$ times, so $A\left(n x+n^{*} x^{*}\right)$ is the anticipated productivity of any firm performing the task there. Note too that the price quoted to Western firms includes the anticipated cost of offshoring, since a subcontractor with its capacity for task $i$ in East will incur such a cost if it performs the task on behalf of a firm headquartered in West.

Now consider a local deviation by a firm that instead locates its capacity for task $i$ in West. Let the deviant quote the prices $\tilde{p}_{i}^{E}=\infty$ and $\tilde{p}_{i}^{W}=p_{i}^{W}-$ $\varepsilon$ for some small $\varepsilon$. At these prices, the deviant will attract as second-stage customers all of the Western firms but none of the Eastern firms, and so it will achieve a scale of $n^{*} x^{*}$ and a productivity of $A\left(n^{*} x^{*}\right)$. This local deviation will be profitable unless

$$
\frac{w^{*}}{A\left(n^{*} x^{*}\right)}>\frac{w \beta t(i)}{A\left(n x+n^{*} x^{*}\right)} .
$$

Therefore, a necessary condition for all firms to locate task $i$ in East is $i \leq I$, where $I$ is defined by

$$
I \equiv \min \left\{\max \left\{0, t^{-1}\left(\frac{1}{\beta} \frac{w^{*}}{w} \frac{A\left(n x+n^{*} x^{*}\right)}{A\left(n^{*} x^{*}\right)}\right)\right\}, 1\right\} .
$$

The minimum and maximum in (1) guarantee that $I=0$ if no task can be concentrated in East without threat that a deviant firm would switch its location so as to serve Western firms, and that $I=1$ if all tasks are immune to local deviations of this sort. Equation (1) provides a limit on what tasks can be concentrated in East. For $i>I$, the offshoring costs are too high relative to the potential productivity gains from a greater scale of production, $A\left(n x+n^{*} x^{*}\right) / A\left(n^{*} x^{*}\right)$, and the benefit or cost of any differences in wages, $w^{*} / w$, to support an equilibrium with capacities for task $i$ concentrated in East. The threshold task $I$ (if internal) is the task that is equally costly to perform 
for all Western firms in East at productivity $A\left(n x+n^{*} x^{*}\right)$ or in West at productivity $A\left(n^{*} x^{*}\right)$. Clearly, the threshold $I$ decreases with the relative wage $w / w^{*}$, increases with aggregate output $n x$ in the East, and decreases with aggregate output $n^{*} x^{*}$ in West. ${ }^{13}$ An increase in aggregate output in East reduces the attractiveness of "going it alone" in West, whereas an increase in aggregate output in West makes such a strategy more palatable.

Next consider a global deviation by some firm when all others locate task $i$ in East. Under this strategy, the deviant firm prices so as to be able to perform the task at global scale; that is, it undercuts the prices set by the others in the conjectured equilibrium (which equal their expected costs of self-provision). By setting prices $\tilde{p}_{i}^{E}=p_{i}^{E}-\varepsilon$ and $\tilde{p}_{i}^{W}=p_{i}^{W}-\varepsilon$, the deviant can sell to everyone and achieve productivity $A\left(n x+n^{*} x^{*}\right)$. The global deviation will be profitable if

$$
\begin{aligned}
\tilde{\pi}(i) \equiv & {\left[\frac{w}{A\left(n x+n^{*} x^{*}\right)}-\frac{\beta t(i) w^{*}}{A\left(n x+n^{*} x^{*}\right)}\right] n x } \\
& +\left[\frac{\beta t(i) w}{A\left(n x+n^{*} x^{*}\right)}-\frac{w^{*}}{A\left(n x+n^{*} x^{*}\right)}\right] n^{*} x^{*} \\
> & 0,
\end{aligned}
$$

considering that the deviant will need to pay offshoring costs for serving Eastern firms, but not for serving Western firms.

Let us define a task

$$
J \equiv \min \left\{\max \left\{0, t^{-1}\left(\frac{1}{\beta} \frac{w n x-w^{*} n^{*} x^{*}}{w^{*} n x-w n^{*} x^{*}}\right)\right\}, 1\right\} .
$$

Suppose for concreteness that $w>w^{*}$; that is, that East is the country with the higher wage rate. We prove the following lemma. ${ }^{14}$

LEMMA 1: If $w>w^{*}$, either (i) $\tilde{\pi}(i)>0$ or $\tilde{\pi}(i)<0$ for all $i$ or (ii) $J>0$ and $\tilde{\pi}(i)>0$ for $i<J$, while $\tilde{\pi}(i)<0$ for $i>J$.

Hence, $i \geq J$ is necessary for concentration of task $i$ in the high-wage East. ${ }^{15}$ If interior, the threshold $J$ is the task for which concentrated performance in East yields the same aggregate cost as concentration in West. For this task, a global deviation is marginally unprofitable, because a deviant cannot achieve any cost savings by switching locations. The threshold $J$ increases with $w / w^{*}$, because a higher relative wage in East raises the relative cost of performing

\footnotetext{
${ }^{13}$ The last statement follows from the fact that $A(\cdot)$ is increasing and concave.

${ }^{14}$ Proofs of the three lemmas are provided in the Supplemental Material (Grossman and RossiHansberg (2012)).

${ }^{15}$ If East were the low-wage country, the necessary condition would instead be $i \leq J$.
} 
tasks there. The threshold also increases with $n^{*} x^{*}$, because the greater is the aggregate output in West, the greater are the offshoring costs that result from performing a task in East. By similar reasoning, the threshold $J$ declines with $n x$.

If neither a local deviation nor the global deviation is profitable for some task $i$, then there exists a location equilibrium in which all firms site that task in East. Evidently, the necessary and sufficient conditions for this are $i \leq I$ and $i \geq J$.

Now consider the possibility that all firms locate their capacity to perform task $i$ in West. By analogous reasoning, a deviant might locate in East with the intention of serving only Eastern firms or with the intention of serving all firms. The local deviation will be profitable unless

$$
\frac{w}{A(n x)}>\frac{\beta t(i) w^{*}}{A\left(n x+n^{*} x^{*}\right)},
$$

where the left-hand side is the per-unit cost of serving the Eastern firms from East and the right-hand side is what the firms expect to pay by offshoring this task in West. We can express a necessary condition for concentration of task $i$ in West as $i \leq I^{*}$, where $I^{*}$ is defined by

$$
I^{*} \equiv \min \left\{\max \left\{0, t^{-1}\left(\frac{1}{\beta} \frac{w}{w^{*}} \frac{A\left(n x+n^{*} x^{*}\right)}{A(n x)}\right)\right\}, 1\right\} .
$$

The threshold task $I^{*}$, if it is interior, is the one that is equally costly to perform for all Eastern firms in East or in West, considering that the former avoids offshoring costs but sacrifices scale economies. This threshold increases with $w / w^{*}$, because the relative cost of performing tasks in East increases with the relative wage there. Task $I^{*}$ increases with $n^{*} x^{*}$ and declines with $n x$, inasmuch as the former expands the benefit to Eastern firms from joining the others in West, whereas the latter reduces the cost of "going it alone" in East.

When all firms locate task $i$ in West, a global deviation will be profitable if $-\tilde{\pi}(i)>0$; that is, if the task can be performed at lesser total cost in East than in West. Again assuming for concreteness that $w \geq w^{*}$, we can write the necessary condition as $i \leq J$, where $J$ is defined as before. The necessary and sufficient conditions for existence of a location equilibrium for task $i$ with all firms concentrated in West are $i \leq I^{*}$ and $i \leq J$.

Now consider Figure 1(a), which shows one possible ordering of the threshold tasks $I, I^{*}$, and $J$. The figure is drawn under the assumption that $w>w^{*}$. We have seen that there exists a location equilibrium for each task $i \in[0, J]$ in which the task is concentrated in West and performed there by or on behalf of all firms. There exists no location equilibrium with concentration in East for any task in this range, because such an outcome would be undermined by a global deviation. For a task with index $i \in(J, I)$, there exists a location equilibrium with concentration in East, but none with concentration in West, because 
(a)

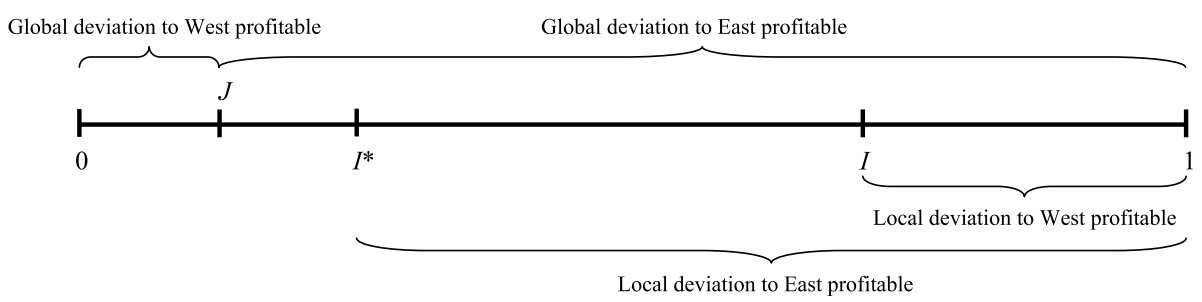

(b)

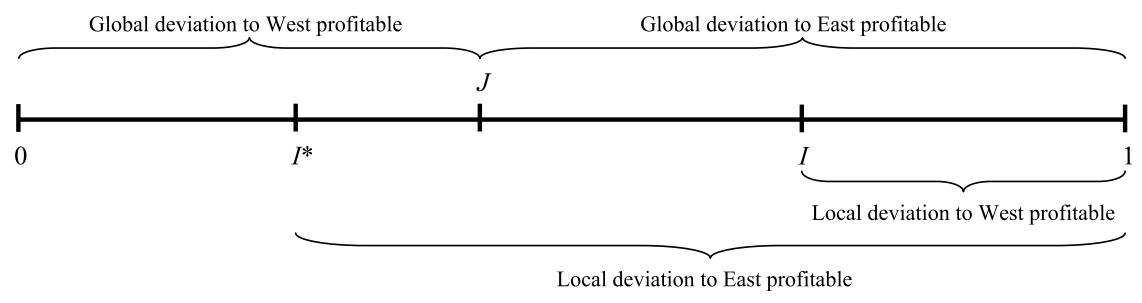

FIGURE 1.-Profitable local and global deviations.

the latter allocation would be susceptible to a global deviation. Finally, a task with index $i>I$ cannot be concentrated in East or in West in the location and pricing stage, because a local deviation would undermine either such placement. For such a task, we must now examine the possibility that Eastern firms site their capacities in East and Western firms do so in West.

Suppose that all firms locate their capacities for task $i$ in the country of their headquarters and that all firms price with the intention of serving only firms that share their country of origin. Let the Eastern firms quote the price $p_{i}^{E}=w / A(n x)$ for outsourcing task $i$ to other Eastern firms, while setting a prohibitive price for firms in West. Similarly, let the Western firms quote the price $p_{i}^{W}=w^{*} / A\left(n^{*} x^{*}\right)$ to other Western firms, but quote a prohibitive price for serving those headquartered in East. With these locations and prices, the subsequent production pattern is dispersed; the Eastern firms perform or procure the task in East, while the Western firms do so in West. A postulated equilibrium with dispersed production of task $i$ is susceptible to a deviation by a firm that locates in East and prices to achieve global scale or by one that locates in West and does similarly. It is readily seen that performing task $i$ in East with prices just below those indicated above will be profitable if $i<I$ and that performing the task in West at such prices will be profitable if $i<I^{*}$. Therefore, the necessary and sufficient conditions for existence of an equilibrium for task $i$ with dispersed locations and production are $i \geq I$ and $i \geq I^{*}$.

We return to Figure 1(a). We previously identified (concentrated) location equilibria for all tasks with $i \in[0, I]$ and we have now verified that a location 
equilibrium with dispersed capacity locations and task performance exists for all tasks $i \in[I, 1]$. Therefore, we have established the existence of a location equilibrium for every task in the unit interval for the case of $J<I^{*}<I$, and we have ruled out alternative sitings of any task except those at the thresholds. In the location equilibria that we have just described, every producer is indifferent between performing any task in-house or procuring it via outsourcing. But the country in which each task is performed by (or for) every firm is fully determined.

Now consider Figure 1(b), which depicts an alternative ordering of $I, I^{*}$, and $J$. By familiar reasoning, there exists a location equilibrium for all tasks $i \in\left[0, I^{*}\right]$ that has concentrated capacity location and task performance in West. For these tasks (except the threshold task $I^{*}$ ), concentration in East would be undermined by a local deviation. Tasks with $i \in[J, I]$ have a location equilibrium with concentration in East, but those in the interior of this interval cannot be concentrated in West. Additionally, for tasks with index $i \in[I, 1]$, there exists a location equilibrium with dispersed location and production. But note that none of these outcomes is possible for any task $i \in\left(I^{*}, J\right)$. For a task in this range, if all firms were to locate capacity in East, a global deviation to West would be profitable, but if all firms were to locate in West, a local deviation to East would be profitable, and since $i<I$, if all firms were to locate in the country of their headquarters and price to serve only their compatriots, an Eastern firm could profitably deviate by pricing to capture sales to Western firms. Evidently, for any task $i \in\left(I^{*}, J\right)$, there is no location equilibrium with concentrated location and production, and no equilibrium with dispersed location and production.

There is a further possibility that we have yet to consider. Suppose that all firms locate capacity for task $i \in\left[I^{*}, J\right]$ in the country of their headquarters. Let the Eastern firms price at cost assuming global scale, namely

$$
p_{i}^{E}=\frac{w}{A\left(n x+n^{*} x^{*}\right)} \quad \text { and } \quad p_{i}^{W}=\frac{w \beta t(i)}{A\left(n x+n^{*} x^{*}\right)} .
$$

Let the Western firms price to compete only for local sales; that is, they set a price equal to $w^{*} / A\left(n^{*} x^{*}\right)$ for sales to Western firms and a prohibitive price for sales to Eastern firms. In the subsequent production stage, each Western firm prefers to procure task $i$ from one of its Eastern counterparts than to perform it in-house or to procure from another firm in West. Clearly, no Eastern firm has an incentive to deviate, because all firms are pricing at cost. As for the Western firms, a deviant must price below $p_{i}^{E}$ to attract sales from East. If it did so, it could not cover the associated losses with any profits on sales to fellow Western firms, because these other firms have the option to self-provide and they can perform the task for themselves at the same cost as could the deviant. ${ }^{16}$ If the

\footnotetext{
${ }^{16}$ The fact that a Western firm pricing at $p_{i}^{E}=w / A\left(n x+n^{*} x^{*}\right)-\varepsilon$ suffers losses on its sales to Eastern firms follows directly from the fact that $i>I^{*}$. Even if productivity in East were only
} 
deviant firm were to price above the anticipated cost of serving firms in West, it would find no takers for its offer.

Evidently, there exists a location equilibrium for any task $i \in\left[I^{*}, J\right]$ that has dispersed location of capacities but concentrated production. For tasks in this range, Eastern firms locate capacity in East and either self-provide or procure from another Eastern firm, whereas Western firms locate in West but ultimately procure the task from an Eastern firm under an outsourcing arrangement.

Using a similar approach, we can now describe the location equilibrium for every task under all possible orderings of the threshold tasks. We do so with the aid of Figure 2, which is drawn under the assumption that $w>w^{*}$. In Grossman and Rossi-Hansberg (2012), we prove the following lemma.

\section{LEMMA 2: If $w>w^{*}$, then $J<I$ implies $I>I^{*}$.}

This lemma rules out the possibility that $I, I^{*}$, and $J$ are ordered such that $J<I<I^{*}$. The figure depicts the remaining five possible orderings of the threshold tasks.

Figure 2(a) reproduces the ordering of Figure 1(a). As we have seen, the tasks with the lowest offshoring costs have concentrated location and production in the low-wage West. These tasks are indicated in the figure by $\mathcal{W}^{c}$ (where the superscript $c$ denotes that for these tasks, capacity and production are concentrated in West). The tasks with intermediate offshoring costs have concentrated location and production in the high-wage East and are indicated by $\mathcal{E}^{c}$, and the tasks with the highest offshoring costs have dispersed location and production, as indicated by $\mathcal{D}$.

Similarly, Figure 2(b) reproduces the ordering of Figure 1(b). There are ranges with concentrated location and production in East and in West, and a range with dispersed location and production. In addition, there is a range of tasks with $i \in\left(I^{*}, J\right)$ for which location is dispersed but production is concentrated in East. We denote this range by $\mathcal{E}^{o}$ to indicate that they are performed in East, but with offshore outsourcing by firms in West.

The remaining panels can be understood similarly. When $I^{*}<I<J$, as in Figure 2(c), some tasks are performed only in West and some only in East, but Western firms never locate their capacity for any task in East. When $I<I^{*}$, there is no task that is performed only in East. In Figure 2(d), Eastern firms do locate their capacity in East for tasks with $i \in\left(J, I^{*}\right)$, but they outsource the performance of these task to Western partners in the subsequent production stage (region $\mathcal{W}^{\circ}$ ). In Figure 2(e), tasks with low offshoring costs have location

$A(n x)$, it would be more costly to serve these firms from West than from East, based on the definition of $I^{*}$ in (3). A fortiori, it is more costly to serve them from the West when the Eastern cost reflects the productivity of global scale. 
$I^{*} \leq I$

(a)

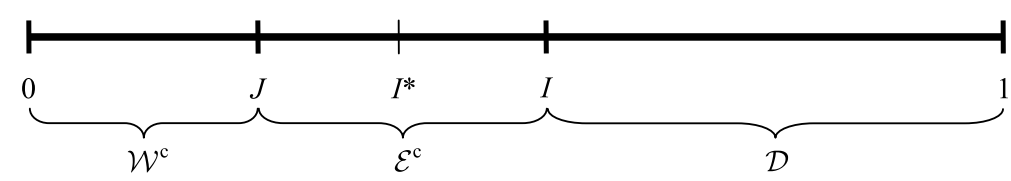

(b)

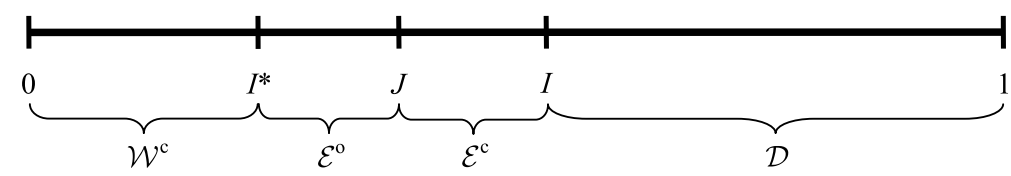

(c)

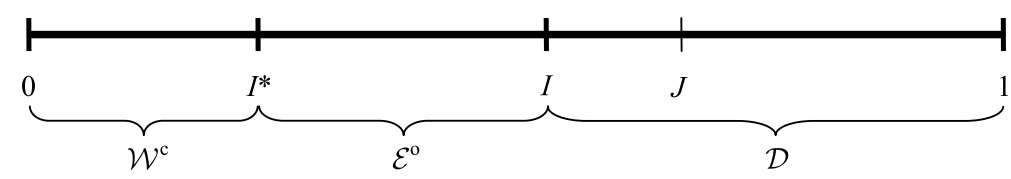

$\boldsymbol{I}<\boldsymbol{I}^{*}$

(d)

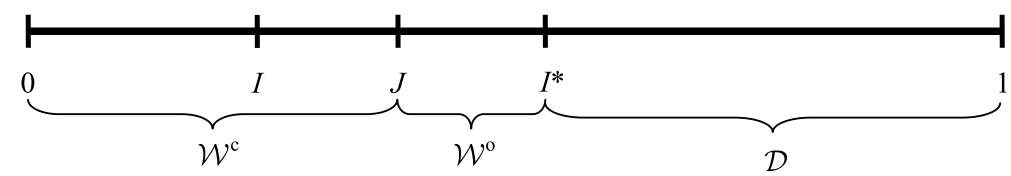

(e)

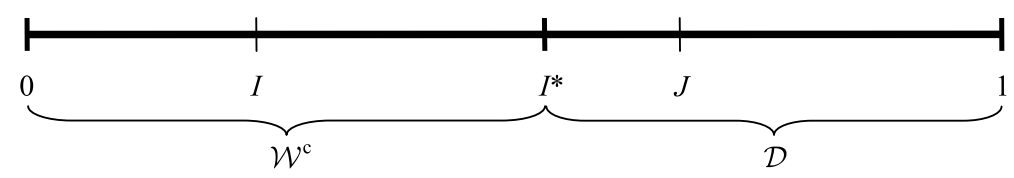

FIGURE 2.-Location equilibrium for all tasks.

and production concentrated in West, while those with high offshoring costs have location and production dispersed.

In what follows, we denote by $\mathcal{E} \equiv \mathcal{E}^{c} \cup \mathcal{E}^{o}$ and $\mathcal{W} \equiv \mathcal{W}^{c} \cup \mathcal{W}^{o}$ the sets of all tasks performed in East and West, respectively. ${ }^{17}$ We summarize the allocation of tasks to countries more formally in the following proposition.

${ }^{17}$ We characterize the location of tasks using only open intervals so as to exclude the boundaries of the sets defined by the thresholds $I, I^{*}$, and $J$. At these boundaries there can be two subgame perfect equilibria of the location game. Since this only happens in a set of measure 
Proposition 1: Suppose $w>w^{*}$ and that $I, I^{*}$, and $J$ are defined by (1), (3), and (2), respectively.

(i) If $I \geq I^{*}$, performance of every task $i \in \mathcal{W}^{c}=\left[0, \min \left\{I^{*}, J\right\}\right)$ is concentrated in West, performance of every task $i \in \mathcal{E}=\left(\min \left\{I^{*}, J\right\}, I\right)$ is concentrated in East, and performance of every task $i \in \mathcal{D}=(I, 1]$ is dispersed. Moreover, if $I^{*}<J$, each Western firm outsources the performance of every task $i \in \mathcal{E}^{o}=$ $\left(I^{*}, \min \{J, I\}\right)$ to some Eastern firm.

(ii) If $I<I^{*}$, performance of every task $i \in \mathcal{W}=\left[0, I^{*}\right)$ is concentrated in West and performance of every task $i \in \mathcal{D}=\left(I^{*}, 1\right]$ is dispersed. Moreover, if $J<I^{*}$, each Eastern firm outsources the performance of tasks $i \in \mathcal{W}^{\circ}=(J, I)$ to some Western firm.

We conclude this section with a comment about the pattern of specialization revealed by Figure 2 and described in Proposition 1. Recall that we have arbitrarily tabbed West as the low-wage country. For all possible orderings of $I, I^{*}$, and $J$, the set of tasks performed in West has lower offshoring costs than the set of tasks performed in East, which in turn has lower offshoring costs than the set that is dispersed. After we develop the conditions for a general equilibrium, we (in Proposition 6) tie this pattern of specialization to the relative amounts of final output produced in each country.

\subsection{Efficiency of Task Allocation}

In this section, we characterize the efficient allocation of tasks given wages and aggregate outputs, and describe the inefficiencies inherent in the market allocation.

It is clear from the symmetry of the various firms headquartered in a country that an efficient allocation requires all Western firms to perform (or procure) a given task in the same location, and that Eastern firms should do likewise. The remaining issues that must be addressed are (i) whether performance of a task $i$ should be concentrated or dispersed and (ii) if concentrated, in which country it should be performed. We begin with the latter question first.

If performance of task $i$ is concentrated in a country, the productivity with which it is performed is $A\left(n x+n^{*} x^{*}\right)$ no matter which location is chosen. The total cost of performing the task inclusive of offshoring costs is

$$
\frac{w}{A\left(n x+n^{*} x^{*}\right)} n x+\frac{w \beta t(i)}{A\left(n x+n^{*} x^{*}\right)} n^{*} x^{*}
$$

if performed in East and

$$
\frac{w^{*} \beta t(i)}{A\left(n x+n^{*} x^{*}\right)} n x+\frac{w^{*}}{A\left(n x+n^{*} x^{*}\right)} n^{*} x^{*}
$$

zero that contains a maximum of three points in the set $[0,1]$, the multiplicity of outcomes at the boundaries is irrelevant for the general equilibrium of the model or any of our substantive results. 
if performed in West. The former exceeds the latter if and only if $i<J$, where $J$ is defined in (2). In other words, if $J$ is interior in $[0,1]$, then task $J$ can be performed at the same aggregate cost in either location. Considering the different scales of final output in the two countries, tasks with smaller offshoring costs than $J$ are more cheaply performed in the low-wage West, and tasks with higher offshoring costs than $J$ are more cheaply performed in the high-wage East.

Now consider the efficient choice of concentration versus dispersion. Let us compare the option of concentrated performance of task $i$ in East with the option of serving Eastern firms from East and Western firms from West. The former yields lower aggregate costs if and only if

$$
\frac{w}{A(n x)} n x+\frac{w^{*}}{A\left(n^{*} x^{*}\right)} n^{*} x^{*}>\frac{w}{A\left(n x+n^{*} x^{*}\right)} n x+\frac{w \beta t(i)}{A\left(n x+n^{*} x^{*}\right)} n^{*} x^{*}
$$

or $i<\hat{I}$, where $\hat{I}$ is defined by

$$
\begin{aligned}
\hat{I} \equiv & \min \left\{\operatorname { m a x } \left\{0, t^{-1}\left(\frac { 1 } { \beta } \left(\frac{w^{*}}{w} \frac{A\left(n x+n^{*} x^{*}\right)}{A\left(n^{*} x^{*}\right)}\right.\right.\right.\right. \\
& \left.\left.\left.\left.+\left[\frac{A\left(n x+n^{*} x^{*}\right)}{A(n x)}-1\right] \frac{n x}{n^{*} x^{*}}\right)\right)\right\}, 1\right\} .
\end{aligned}
$$

By comparing (1) and (4), we see that $\hat{I}>I$; that is, the marginal task that is immune to a profitable local deviation by Western firms has a lower offshoring cost than the marginal task that can be more cheaply performed only in East compared to the alternative of dispersed production. This reflects the fact that a local deviant siting its capacity in West can profit from sales to Western firms without taking into account the negative externality that its action imposes on Eastern firms. We can define analogously a task $\hat{I}^{*}$ such that the aggregate cost of concentrating task $\hat{I}^{*}$ in West equals the aggregate cost of performing the task in dispersed locations. By similar reasoning, $\hat{I}^{*}>I^{*}$.

The efficient allocation is readily characterized. Tasks with $i>\max \left\{\hat{I}, \hat{I}^{*}\right\}$ are optimally dispersed; Eastern firms should be served from East and Western firms should be served from West. Among the rest, those with $i<J$ (if any) are optimally concentrated in West and those with $i>J$ are optimally concentrated in East.

It should now be apparent that, in general, the equilibrium allocation exhibits two types of inefficiency. First, the margin between concentration and dispersion generates too little offshoring relative to what would be globally efficient. In equilibrium, the tasks with $i>\max \left\{I, I^{*}\right\}$ are dispersed, whereas it is efficient to separate performance of only those tasks with $i>\max \left\{\hat{I}, \hat{I}^{*}\right\}$. Since $\hat{I}>I$ and $\hat{I}^{*}>I^{*}$, the equilibrium has dispersed tasks that optimally would be 
concentrated. This inefficiency reflects the negative externality that producers in one country impose on those in the other when they choose to "go it alone."

Second, efficiency requires that the division of tasks concentrated in West versus East be governed by $J$. The same is true of the equilibrium allocation in Figure 2(a), but not so in Figure 2(b), (c), or (d). In each of these latter cases, there exists a range of tasks that optimally would be concentrated in one country, but concentration there is undermined by a profitable local deviation to the other. Instead, these tasks are concentrated in the "wrong" country, with firms in the other locations served by outsourcing. Take, for example, the tasks $i \in\left(I^{*}, J\right)$ in Figure 2(b). Since $i<J$, it would be less costly to perform these tasks in West than in East. But these tasks are not performed in West in the equilibrium, because a deviant would move the task to East and attract other Eastern producers as customers. Instead, performance of the task is concentrated in East, with Western firms served by their Eastern counterparts.

We summarize our discussion of the efficiency of task allocation in the following proposition.

PROPOSITION 2: (i) For any task in $\mathcal{D}$ that lies in the interval $\left(\max \left\{I, I^{*}\right\}\right.$, $\left.\max \left\{\hat{I}, \hat{I}^{*}\right\}\right)$, aggregate cost would be reduced by concentrating production in some country. (ii) Aggregate cost would be reduced by concentrating production of tasks $i \in \mathcal{E}^{\circ}$ in West and of tasks $i \in \mathcal{W}^{\circ}$ in East.

\subsection{General Equilibrium}

In Section 2.1 we described the location of every task for given $n, n^{*}, x, x^{*}, w$, and $w^{*}$. Of course, the locations of the various tasks affect costs, profitability, and factor demands. Therefore, the equilibrium numbers of firms in each country, the per-firm output levels, and the factor prices are in turn functions of where the various tasks are performed. In this section, we provide the remaining requirements for a general equilibrium. These conditions are more familiar. They reflect the fact that firms practice markup pricing, relative outputs match relative demands, free entry drives profits to zero, and factor markets clear in every country.

Let $c$ and $c^{*}$ denote the unit cost of a typical final good for a firm headquartered in East and West, respectively. As defined before, $\mathcal{E}$ denotes the set of tasks performed only in East, including those (if any) that are performed by Eastern firms on behalf of Western counterparts. Similarly, $\mathcal{W}$ represents the set of tasks performed only in West (including $\mathcal{W}^{\circ}$ ), and $\mathcal{D}$ denotes the set of tasks that are performed locally by firms in both countries. All tasks in $\mathcal{E}$ represent offshoring for firms headquartered in West, while tasks in $\mathcal{W}$ represent offshoring for firms headquartered in East. There is no offshoring of the tasks 
in $\mathcal{D}$. In view of the costs of offshoring and the different scales of output for tasks that are traded and not, we have

$$
c=\frac{w M(\mathcal{E})}{A\left(n x+n^{*} x^{*}\right)}+\frac{w^{*} T(\mathcal{W})}{A\left(n x+n^{*} x^{*}\right)}+\frac{w M(\mathcal{D})}{A(n x)}
$$

and

$$
c^{*}=\frac{w T(\mathcal{E})}{A\left(n x+n^{*} x^{*}\right)}+\frac{w^{*} M(\mathcal{W})}{A\left(n x+n^{*} x^{*}\right)}+\frac{w^{*} M(\mathcal{D})}{A\left(n^{*} x^{*}\right)},
$$

where $M(\mathcal{Z})$ is the Lebesgue measure of $\mathcal{Z}$ for $\mathcal{Z}=\{\mathcal{E}, \mathcal{W}, \mathcal{D}\}$ and $T(\mathcal{Z}) \equiv$ $\int_{i \in \mathcal{Z}} \beta t(i) d i$ for $\mathcal{Z}=\mathcal{E}$ and $\mathcal{W}$. So $T(\mathcal{Z}) / A\left(n x+n^{*} x^{*}\right)$ is the total amount of labor per unit of output needed to perform the tasks in $\mathcal{Z}$ for an offshore firm when labor productivity is $A\left(n x+n^{*} x^{*}\right) .{ }^{18}$ In (5), the three terms denote the total per-unit cost to a firm headquartered in East of the tasks that are performed only in East, the tasks that are performed only in West, and the tasks that are dispersed, respectively. The interpretation of (6) is similar.

Given $c$ and $c^{*}$, the firms practice markup pricing. This yields, via the demand functions, a relationship between relative costs of Eastern and Western firms and relative quantities produced (and consumed) of the different varieties, namely

$$
\frac{x}{x^{*}}=\left(\frac{c}{c^{*}}\right)^{-\sigma}
$$

where, as defined before, $\sigma>1$ denotes the elasticity of substitution between any pair of varieties. Free entry drives variable profits to the level of fixed costs, which are $s f$ for a firm headquartered in East and $s^{*} f$ for a firm headquartered in West, where $s$ and $s^{*}$ are the salaries of managers in East and West, respectively. By familiar calculations, the zero-profit conditions imply

$$
s=\frac{c x}{f(\sigma-1)}
$$

and

$$
s^{*}=\frac{c^{*} x^{*}}{f(\sigma-1)}
$$

\footnotetext{
${ }^{18} \mathrm{We}$ assume $\mathcal{E}, \mathcal{W}$, and $\mathcal{D}$ are elements of the Borel $\sigma$-algebra and that $t(\cdot)$ is Lebesgue measurable. For the case in which $w \neq w^{*}$, we find that the sets $\mathcal{E}, \mathcal{W}$, and $\mathcal{D}$ are connected intervals, so the integral that defines $T(\cdot)$ is a standard Riemann integral. If $w=w^{*}$, the theory imposes no structure on the sets $\mathcal{E}$ and $\mathcal{W}$ ( $\mathcal{D}$ is still a connected interval). In this case, we restrict attention to sets $\mathcal{E}$ and $\mathcal{W}$ that are elements of the Borel $\sigma$-algebra and use the Lebesgue integral. Of course, this restriction has no effect on the general equilibrium properties of our economy.
} 
Finally, we have the factor-market clearing conditions. Managers are employed only in headquarters, where they perform activities that are independent of scale. In each country, $f$ managers are needed per firm, which implies

$$
n f=H
$$

and

$$
n^{*} f=H^{*}
$$

Workers in each country are employed in tasks that are performed locally by national firms and in affiliates of foreign firms. Tasks in $\mathcal{E}$ do not use any Western labor and tasks in $\mathcal{W}$ do not use any Eastern labor. Considering the demands by local and foreign firms for the tasks that are concentrated in one country and for those that are dispersed, we have

$$
\frac{M(\mathcal{E})}{A\left(n x+n^{*} x^{*}\right)} n x+\frac{T(\mathcal{E})}{A\left(n x+n^{*} x^{*}\right)} n^{*} x^{*}+\frac{M(\mathcal{D})}{A(n x)} n x=L
$$

and

$$
\frac{T(\mathcal{W})}{A\left(n x+n^{*} x^{*}\right)} n x+\frac{M(\mathcal{W})}{A\left(n x+n^{*} x^{*}\right)} n^{*} x^{*}+\frac{M(\mathcal{D})}{A\left(n^{*} x^{*}\right)} n^{*} x^{*}=L^{*}
$$

The three terms on the right-hand side of (12) are, respectively, the labor employed in East to perform concentrated tasks (tasks in $\mathcal{E}$ ) by or on behalf of Eastern firms, the labor employed in East to perform concentrated tasks by or on behalf of Western firms, and the labor employed by Eastern firms in tasks that are not traded (tasks in $\mathcal{D}$ ). The interpretation of the terms in (13) is analogous.

Let $w^{*}=1$ be the numéraire. Then a general equilibrium is defined as follows.

DEFINITION 2: A general equilibrium comprises numbers of firms, $n$ and $n^{*}$, output levels, $x$ and $x^{*}$, unit costs, $c$ and $c^{*}$, managers' wages, $s$ and $s^{*}$, and the relative workers' wage $w$, as well as capacity location and procurement decisions, $\mathcal{E}^{c}, \mathcal{E}^{o}, \mathcal{W}^{c}, \mathcal{W}^{o}$, and $\mathcal{D}$, and sets of task prices, $\left\{p_{i}^{E}\right\}$ and $\left\{p_{i}^{W}\right\}$, such that the following statements hold:

(i) Decisions $\mathcal{E}^{c}, \mathcal{E}^{o}, \mathcal{W}^{c}, \mathcal{W}^{o}$, and $\mathcal{D}$, and prices $p_{i}^{E}$ and $p_{i}^{W}$ constitute a location equilibrium for every task $i \in[0,1]$.

(ii) Agents maximize utility, firms maximize profits, there is free entry, and factor markets clear. Namely, equations (5)-(13) are satisfied. 
Our next task is to characterize the patterns of specialization that can emerge in general equilibrium. Before doing so, we conclude this section by reporting the existence of a general equilibrium for this economy. ${ }^{19,20}$

Proposition 3: A general equilibrium exists.

\section{PATTERNS OF SPECIALIZATION}

In this section, we explore the patterns of specialization and associated wages that can emerge when offshoring takes place between countries with similar relative factor endowments and technological capabilities. We characterize the general equilibrium analytically and use numerical examples to illustrate the outcomes that can arise.

We denote the world aggregate endowment of managers by $\bar{H}$ and the world aggregate endowment of labor by $\bar{L}$. We consider the trade equilibria that can arise for various divisions of $\bar{H}$ and $\bar{L}$ across East and West, always assuming that $H / L=H^{*} / L^{*}$. When East and West are equal in size, $L / L^{*}=1$. When East is much larger, $L / L^{*} \rightarrow \infty$. We are interested in how the relative size of the two countries affects the pattern of specialization and relative wages. It turns out that the country with the greater output of the final good always enjoys a higher wage. We record this result in the following lemma and use it repeatedly in our characterization of the equilibrium below.

LEMMA 3: $w>1$ if and only if $n x>n^{*} x^{*}$.

The magnitude of offshoring costs - as captured by the parameter $\beta$ - has an important bearing on the nature of the general equilibrium. The following proposition characterizes equilibria for economies with high offshoring costs.

PROPOSITION 4: There exists a finite $\beta_{\mathrm{NO}}$ such that for $\beta>\beta_{\mathrm{NO}}$ :

(i) There exists an $\ell_{H}>1$ such that for $\ell_{H}>L / L^{*}>1 / \ell_{H}$, there is a unique equilibrium characterized by $w=1, x=x^{*}$, and $n=n^{*}$ for $L / L^{*}=1 ; w>1$, $x>x^{*}$, and $n>n^{*}$ for $L / L^{*}>1$; and $w<1, x<x^{*}$, and $n<n^{*}$ for $L / L^{*}<1$.

(ii) As $L / L^{*} \rightarrow \infty$, any equilibrium is characterized by $w>1$ and $n x>n^{*} x^{*}$. As $L / L^{*} \rightarrow 0$, any equilibrium is characterized by $w<1$ and $n x<n^{*} x^{*}$.

We discuss this proposition with the aid of an example, as depicted in Figure 3. This figure shows equilibrium values of $I, I^{*}$, and $J$ (in the upper panel) and of the relative wage $w$ (in the lower panel) for different values of $L$. It is

\footnotetext{
${ }^{19}$ The solution to the nine equations in part (ii) of Definition 2 is unique for given $\mathcal{E}, \mathcal{W}$, and $\mathcal{D}$. However, the sets $\mathcal{E}, \mathcal{W}$, and $\mathcal{D}$ are themselves determined by the equilibrium values of the other variables. This suggests the possibility of multiple equilibria, which we discuss further below.

${ }^{20}$ Proofs of propositions not found in the text are provided in the Appendix.
} 

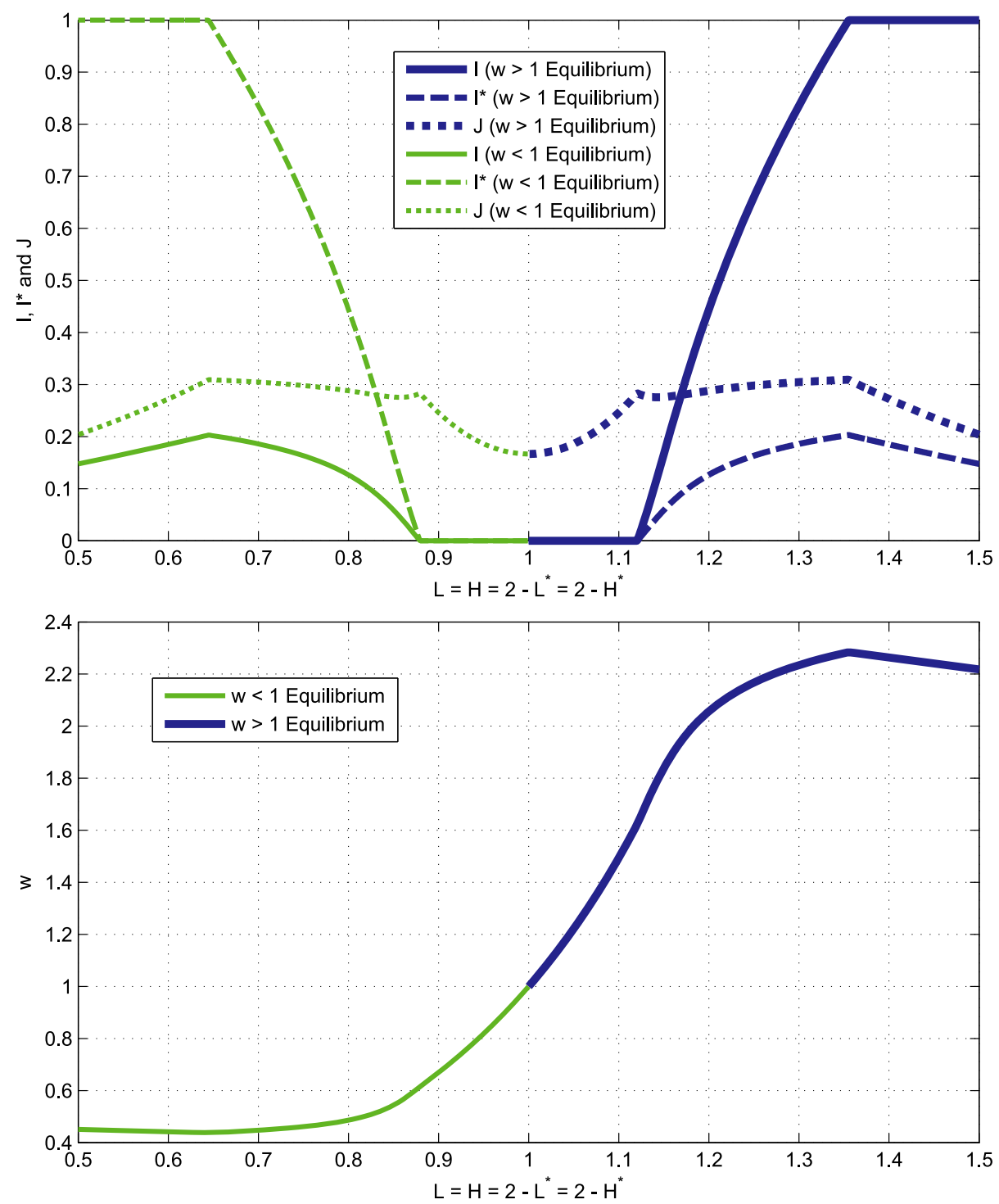

FIGURE 3.-Equilibria and the relative size of countries $(\beta=2, \sigma=2, \theta=0.8, f=1)$.

drawn for a large enough value of $\beta$ such that there is no offshoring between equal-sized countries. ${ }^{21}$ For ease of visual interpretation, we have distinguished

${ }^{21}$ The numerical example uses $\bar{H}=2, \bar{L}=2, t(i)=1+i, A(X)=X^{\theta}$ for $\theta=0.8, f=1, \sigma=2$, and $\beta=2$. 
the outcomes that correspond to equilibria with $w>1$ from those with $w<1$ : the former are depicted with thick, dark curves; the latter are depicted with curves that are thinner and lighter in shade.

Proposition 4(i) implies that when offshoring costs are sufficiently great, firms in equal-sized countries engage in no task trade. The economies of scale provide as always an incentive to concentrate tasks, because firms are more productive when tasks are performed at world scale than at national scale. But when $\beta$ is sufficiently large, this potential source of productivity gain is outweighed by the extra cost of performing tasks far from headquarters, even for the tasks that are easiest to offshore. The fact that $I=0$ means that a potential equilibrium with concentrated performance of task 0 in East would be upset by a local deviation to West, and the fact that $I^{*}=0$ means that a potential equilibrium with concentrated performance of this task in West would be upset by a local deviation to East. The only equilibrium in the location game for task 0 has dispersed location and production; that is, Eastern firms perform the task in East and Western firms perform it in West. The same is true a fortiori for all tasks with indexes $i>0$.

The remainder of Proposition 4(i) for $L / L^{*}=1$ follows readily from this observation. The countries share the same technologies and the same relative factor endowments, and by the predicate of the proposition, they are equal in size. With no offshoring, if wages and scales of production are the same, so too will be unit costs and optimal prices. With similar prices, firms face similar demands and make similar profits, so per-firm outputs indeed are the same in both countries and the numbers of producers are the same as well. It is intuitive that there exists a fully symmetric equilibrium in this case, which mimics the one described by Krugman (1979). The proof in the Appendix establishes the uniqueness of this equilibrium.

For $\beta$ large and $L / L^{*}$ close to but not equal to 1 , it is still true that the costliness of offshoring outweighs the benefit of agglomeration in both countries, even for task 0 . Accordingly, $I=I^{*}=0$ when $\beta>\beta_{\mathrm{NO}}$ and East and West are relatively similar in size. There is no task trade, but the countries are not symmetric. The larger country has a greater scale of production and, consequently, it is more productive in performing all tasks. The lower production costs spell lower prices, greater factors demands, and greater profits. Of course, entry dissipates the higher profits and factor prices adjust to eliminate excess factor demands. As Proposition 4(i) indicates, the larger country must have higher wages, greater output per firm, and more producers in equilibrium.

When $L / L^{*}$ is sufficiently large, however, some task trade must take place for any value of $\beta$. In Figure 3, when $L / L^{*}$ is sufficiently large, $I>I^{*}>0$. According to Proposition 1, this configuration implies that all tasks with $i<I^{*}$ are performed in West and all tasks with $I^{*}<i<I$ are performed in East, while 
those with $i>I$ remain dispersed. ${ }^{22}$ The asymmetry in size means that Western firms stand to benefit greatly from performing the tasks (or having them performed) in the same location as their more-numerous Eastern counterparts. They can do so either by locating their capacity for some tasks in East or by procuring these tasks from East under outsourcing arrangements. But notice too that the task trade can flow in both directions. Indeed, we have two-way task trade in the example illustrated in Figure 3. When the Western firms perform or procure tasks from East, they create an incipient excess demand for Eastern labor. As the Eastern (relative) wage rises, the firms headquartered in East may find an incentive to locate their capacity for some tasks in West, or to procure from there.

The bottom panel of Figure 3 illustrates another feature of equilibrium, as mandated more generally by Proposition 4(ii). As $L / L^{*}$ grows large, the equilibrium wage is greater in the large country than in the small country, even when task trade takes place. There are two reasons for this. First, performance of the tasks with $i>I$ is dispersed in equilibrium; the cost of offshoring these tasks is sufficiently great that all firms prefer to perform or procure them in the country of their headquarters. Since the larger country has a larger scale of output - as also required by Proposition 4(ii) - this country is more productive in performing these tasks. Second, the tasks with the smallest offshoring costs are performed in the smaller country, while those with a moderate offshoring cost are performed in the larger country. This pattern of task trade lowers costs for the firms in the large country relative to those in the smaller country. The greater productivity of firms in the large country translates, in general equilibrium, into greater numbers of firms and higher wages.

We turn next to settings with less onerous offshoring costs, as arise when $\beta<\beta_{\mathrm{NO}}$. The following proposition characterizes the outcomes.

PROPOSITION 5: Suppose that $\beta<\beta_{\mathrm{NO}}$. Then there exists a finite $\ell_{L}>1$ such that the following statements hold:

(i) If $\ell_{L}>L / L^{*}>1 / \ell_{L}$, there are multiple equilibria. In one set of equilibria, $w=1, n x=n^{*} x^{*}$, and the pattern of task trade is indeterminate. Generically, there also exists an equilibrium with $w>1$ and $n x>n^{*} x^{*}$ and an equilibrium with $w<1$ and $n x<n^{*} x^{*}$.

(ii) If $L / L^{*}>\ell_{L}$ or $L / L^{*}<1 / \ell_{L}$, then $w \neq 1$ and $n x \neq n^{*} x^{*}$. As $L / L^{*} \rightarrow \infty$, any equilibrium is characterized by $w>1$ and $n x>n^{*} x^{*}$. As $L / L^{*} \rightarrow 0$, any equilibrium is characterized by $w<1$ and $n x<n^{*} x^{*}$.

Again we use a graphical example to aid in explaining the result. ${ }^{23}$ In keeping with the proposition, Figure 4 depicts three equilibria that exist when resources

\footnotetext{
${ }^{22}$ In this particular case, the tasks with $i \in\left(I^{*}, I\right)$ are performed by Eastern firms inasmuch as the Western firms locate their capacities in West. These firms procure the tasks in this range from Eastern suppliers.

${ }^{23}$ Figure 4 adopts the same parameter values and technologies as Figure 3, except that $\beta=1.1$.
} 

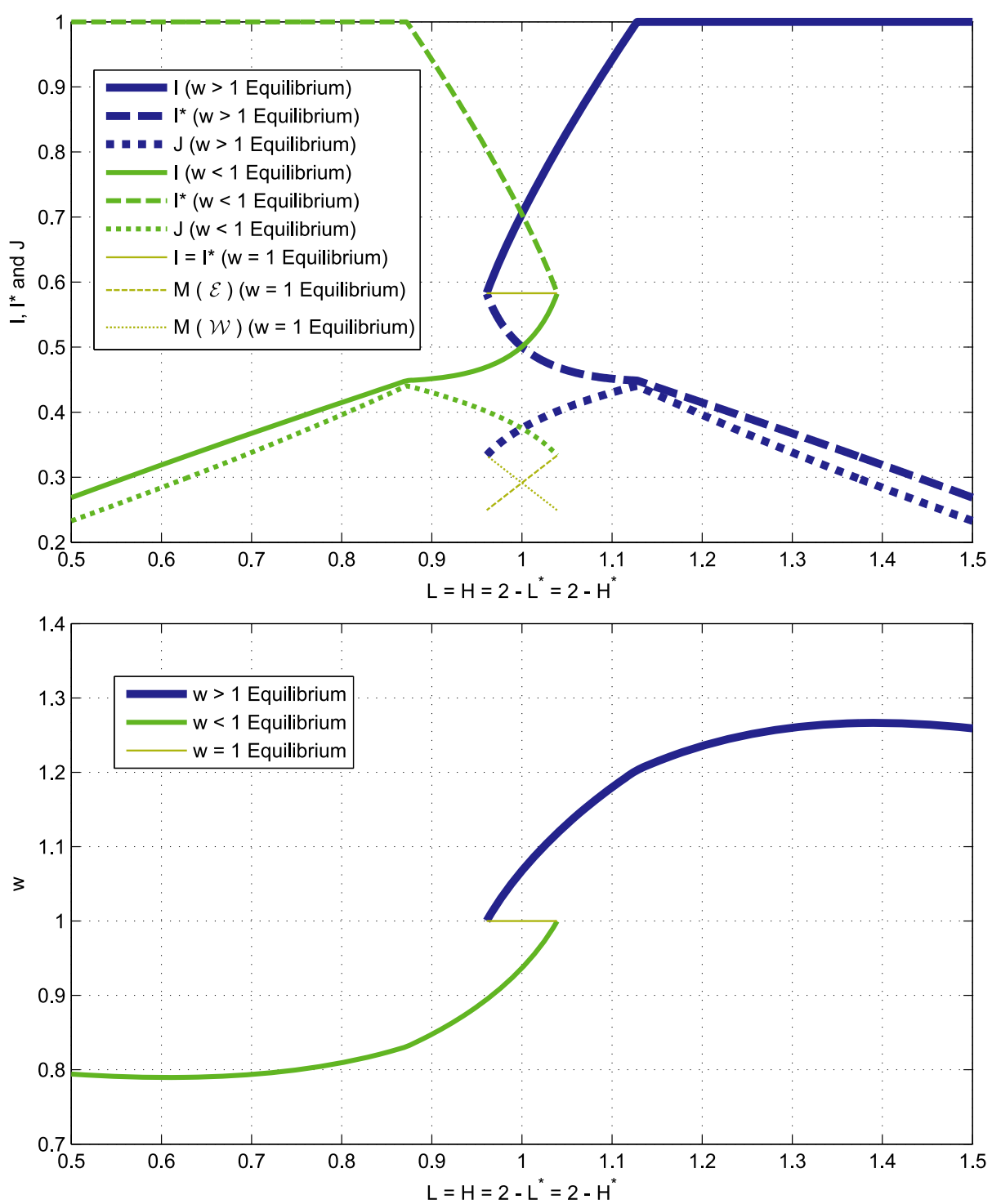

FIGURE 4.-Equilibria and the relative size of countries: low offshoring costs $(\beta=1.1, \sigma=2$, $\theta=0.8, f=1)$.

are almost evenly divided between the countries. For $H$ and $L$ significantly greater than $H^{*}$ and $L^{*}$ (or vice versa), the equilibrium is unique.

The various equilibria depicted in Figure 4 again are distinguished by the thickness and shading of the curves. Consider the three curves in the top panel that are thickest and darkest—which represent equilibria that have $w>1$. 
Here, even when the countries are similar in size, some offshoring takes place. The fact that $0<J<I^{*}<I$ when $L=L^{*}$ implies that tasks with $i \in[0, J)$ are carried out by all firms in West, while those with $i \in(J, I)$ are carried out by all firms in East. In this equilibrium, East has a higher wage and greater final output, despite the fact that the two countries are identical in size and in all other (exogenous) respects. A qualitatively similar equilibrium exists for all $L \geq L^{*}$, as represented by the thick and dark curves to the right of $L=L^{*}=1$.

Notice that the thick curves continue into the region where $L<L^{*}=1$. In other words, we have an equilibrium in which the country that has the smaller factor endowment has the higher wage and exports the tasks that have intermediate offshoring costs. For $L$ slightly smaller than $L^{*}$ and $w>1$, the ordering of the boundary values is $J<I^{*}<I$, just as before. Again, West alone performs the tasks with $i \in[0, J)$, East alone performs the tasks with $i \in(J, I)$, and both countries perform tasks with $i \in(I, 1]$. East generates greater aggregate output than West (i.e., $n x>n^{*} x^{*}$ ) despite its smaller size and correspondingly smaller endowment of managers. The shortfall in the number of its firms compared to West $\left(n<n^{*}\right.$ due to $\left.H<H^{*}\right)$ is more than made up by greater sales per firm $\left(x>x^{*}\right)$. Because East has a greater scale of output, it enjoys a productivity advantage in the tasks that are performed locally by all firms. It also benefits by capturing the tasks that are more difficult to offshore among those that are traded. Its overall cost advantage $\left(c<c^{*}\right)$ underlies its superior sales per variety, which in turn justifies its higher wage and the pattern of specialization.

The requirement for East to perform the tasks with intermediate offshoring costs for producers worldwide strains its small resource base. If $L$ is very much smaller than $L^{*}$, East will lack the workers it would need to perform a sufficiently large range of tasks that are relatively costly to offshore, and then its costs would not be low enough to justify its larger scale and higher wage. In such circumstances, an equilibrium in which the smaller country has the higher wage and the higher aggregate output does not exist.

The curves of medium shade and thickness depict a second equilibrium, analogous to the one we just described except for the reversal of country names and so with $w<1$. Finally, Figure 4 depicts a third type of equilibrium that exists for exactly the same range of $L$ and $L^{*}$ that admits the coexistence of a thick equilibrium with $w>1$ and a medium-thick equilibrium with $w<1$. For a given $L$ and $L^{*}$ in this range, there exists a set of equilibria, all with equal wages in the two countries. Equilibria of this type are represented in Figure 4 by the thinnest set of curves.

When wages are the same in the two countries, all tasks can be performed at lower cost in whichever country has the larger scale of production. No task could be concentrated in the country with the smaller aggregate output, because such an allocation would be undermined by a global deviation to the country with the greater aggregate output. But if the countries are not too different in size and all traded tasks were concentrated in one country, then the two labor markets could not both clear. It follows that an equilibrium with 
equal wages also must have equal aggregate outputs (see Lemma 3); that is, $n x=n^{*} x^{*}$.

With wages and aggregate outputs equalized as they are in the equilibrium depicted by the thin curves, there is nothing to determine the siting of any task for which specialization is viable. Nonetheless, the unit cost equations (5) and (6) and the labor market clearing conditions (12) and (13) determine the measures of traded tasks that are performed in each country and the aggregate offshoring costs borne by producers of either nationality. Also, with $w=w^{*}$ and $n x=n^{*} x^{*}$, the incentives for a deviant supplier to upset an equilibrium with concentrated task performance are the same for both countries. Therefore, $I=I^{*}$ and this common value represents the boundary between traded and nontraded tasks. Figure 4 shows $M(\mathcal{E})$ and $M(\mathcal{W})$ for the equal-wage equilibrium, as well as $I=I^{*}$.

Although the equal-wage equilibrium has an indeterminate pattern of specialization, there are two constraints on the allocation of the traded tasks. First, an equilibrium allocation must satisfy $T(\mathcal{E}) \geq T([0, M(\mathcal{E})])$, because the total offshoring costs for tasks concentrated in East must be at least the cost of offshoring the measure $M(\mathcal{E})$ of tasks that are least costly to offshore. Second, the allocation of tasks must obey $T(\mathcal{E}) \leq T([0, I])-T([0, M(\mathcal{W})])$, because the offshoring costs for tasks concentrated in East can be at most the cost of offshoring the measure $M(\mathcal{E})$ of traded tasks that are most costly to offshore; that is, it is maximized when the measure $M(\mathcal{W})$ of tasks with the lowest offshoring costs locate in West. An equilibrium with equal wages in which the measure $M(\mathcal{E})$ of tasks that are least costly to offshore is concentrated in East is identical to the limiting equilibrium with $w<1$ as $w \rightarrow 1$. In addition, the equilibrium with equal wages in which the measure $M(\mathcal{E})$ of tasks that are most costly to offshore is concentrated in East is identical to the limiting equilibrium with $w>1$ as $w \rightarrow 1$. This explains the convergence of the various thin and thicker curves in Figure 4 . When the gap between $L$ and $L^{*}$ grows too large, one of the constraints must be violated, and so the equal-wage equilibrium ceases to exist. Figure 4 shows that when this equilibrium fails to exist, neither does an equilibrium exist in which the smaller country has the greater wage. ${ }^{24}$

Let us recapitulate. Proposition 4 characterizes the general equilibrium when offshoring costs are high even for the tasks that are easiest to perform

\footnotetext{
${ }^{24} \mathrm{We}$ offer one further observation about the equal-wage equilibrium. Although our model lacks explicit dynamics, the equal-wage equilibrium has a knife-edge property that suggests instability under plausible adjustment mechanisms. Suppose we perturb such an equilibrium by misallocating a few tasks in such a way that total production costs in the two countries remain unchanged. Then the labor markets will fail to clear, which will exert pressure on the relative wage. As soon as the wage equality is broken, the remaining traded tasks will relocate so that those with low offshoring costs are concentrated in the low-wage country and those with intermediate offshoring costs are concentrated in the high-wage country. In other words, a small perturbation creates incentives for a large reallocation of resources and moves the economy into the neighborhood of one of the two equilibria with unequal wages.
} 
at a distance. The country with more resources has higher wages, has more firms, and produces more output per firm. If the size asymmetry is sufficiently great, there is task trade in equilibrium, possibly in both directions. In the example we showed, the smaller country performs the tasks that are easiest to offshore, whereas the larger country performs tasks with intermediate costs of offshoring. Proposition 5 characterizes outcomes when the schedule of offshoring costs is lower. Then, if the countries are close in size, there are multiple equilibria. In one set of equilibria, the countries have equal wages and equal aggregate outputs. Generically, there also exists an equilibrium in which the larger country (in terms of resources) has the greater volume of final output and the higher wage, and an equilibrium in which the smaller country has the greater volume of final output and the higher wage.

The equilibria with unequal wages that we have seen in our numerical examples share a common pattern of task trade. In all of these equilibria, the tasks (if any) that are concentrated in the country with the higher equilibrium wage are more difficult to perform offshore than those (if any) that are concentrated in the country with the lower equilibrium wage. We have also seen in Lemma 3 that the high-wage country also has greater aggregate output. The following proposition characterizes more generally the links between relative wages, relative outputs, and the allocation of tasks to countries.

PROPOSITION 6: In any equilibrium with $w \neq 1$, the pattern of specialization is characterized as follows:

(i) Concentrated performance of tasks with the lowest offshoring costs in the country with low wages and low aggregate output.

(ii) Concentrated performance of tasks with intermediate offshoring costs in the country with high wages and high aggregate output.

(iii) Dispersed performance of tasks with the highest offshoring costs in both countries.

The proposition does not exclude the possibility that no tasks are concentrated in one of the countries or that no tasks are dispersed; that is, one or more of the sets $\mathcal{E}, \mathcal{W}$, and $\mathcal{D}$ may be empty.

The pattern of specialization described by Proposition 6 holds intuitive appeal in light of our previous discussion. Tasks that are very costly to offshore are performed locally, for obvious reasons. For the other tasks, firms in the country with the smaller aggregate output have the most to gain from moving tasks abroad, while those in the country with the larger aggregate output have the most to lose from communication and coordination costs. ${ }^{25}$ Market

\footnotetext{
${ }^{25}$ Aggregate output need not correspond to country size, as the smaller country may produce more per brand if its lower costs generate greater demand. The equilibrium in Figure 4 in which the smaller country has higher wages is one in which its aggregate output of final goods exceeds that in the larger country.
} 
forces drive the tasks that are most difficult to offshore (among those that are traded) to the country with the larger aggregate output to reap the cost savings. In the process, the wage there is bid up, creating incentives for firms in the high-output country to offshore tasks that can readily be moved to the lowwage location. Although this pattern of specialization conforms qualitatively to the dictates of global efficiency, allocation of some tasks will not be efficient due to the presence of national externalities, as we showed in Section 2.2.

Proposition 6 leaves open the possibility that the performance of some tasks is concentrated in one country, but that no task is performed solely in the other. The extent of product differentiation plays a crucial role in determining which country has the greater incentive to engage in offshoring. If, for example, $\sigma=2$, then any equilibrium with task trade must have two-way task trade. In this case, the set of parameters (in addition to $\sigma$ ) for which $I>0$ is exactly the same as the set of parameters for which $I^{*}>0$. The reason is, perhaps, not transparent. A higher wage $w$ directly increases the incentive to offshore in West compared to East. In fact it does so with an elasticity of 2, because it boosts the incentive to offshore in West while dampening the incentive to offshore in East. But a higher $w$ also goes hand in hand with stronger scale economies in East (see Lemma 3), which reduces the relative incentive to offshore in West with an elasticity of $\sigma /(\sigma-1)$. For $\sigma=2$, these effects exactly offset one another, which means that the strength of the incentive to shift tasks to the country with larger scale is matched by the strength of the incentive to shift tasks to the country with the lower wage. When $\sigma<2$, by contrast, there exists a range of relative country sizes for which firms in the low-wage country perform or procure some tasks in the high-wage country, but not vice versa. When $\sigma>2$, there exists a range of relative country sizes for which firms in the high-wage country perform or procure some tasks in the low-wage country, but not vice versa. In either of these situations, the direction of task trade is fully determined by the extent of product differentiation, without regard to the other parameters or functional forms. We record this observation formally in the next proposition.

Proposition 7: Suppose $\beta>\beta_{\mathrm{NO}}$. Then there exists a set of values of $L / L^{*}>$ 1 for which (i) if $\sigma<2$, then $I>I^{*}=0$; (ii) if $\sigma>2$, then $I^{*}>I=0$; and if $\sigma=2$, then $I>0$ if and only if $I^{*}>0$.

We have also studied numerically the link between the pattern of specialization and the extent of increasing returns to scale, the extent of product differentiation, and the size of offshoring costs. For a large set of parameter values, we find that larger size differences between countries generate a broader range of traded tasks and imply larger wage differentials as long as some tasks are performed in both countries. Stronger external economies of scale and higher elasticities of substitution have similar implications for the extent of production sharing and for relative wages. Not surprisingly, a reduction in offshoring costs induces more task trade and tends to improve welfare. 


\section{CONCLUDING REMARKS}

We have developed a theory of task trade between similar countries. When offshoring costs are not too high, firms concentrate certain tasks in particular locations so as to realize external economies of scale. The potential for outsourcing allows them to overcome some aspects of the coordination problem inherent in this. Our theory predicts the pattern of specialization by task for countries that differ only in size. We find that there always exists an equilibrium in which the larger country has higher wages and greater aggregate output of final goods. If offshoring costs are low enough and the countries are not too different in size, there may exist another equilibrium in which the smaller country has the higher wages and greater aggregate output. In either case, the country with the higher wages and output performs the tasks-among those that are concentrated - that are more difficult and costly to offshore.

Our main empirical prediction links the pattern of specialization in tasks to relative wages. To test this prediction, we would need to identify the characteristics of tasks performed in different countries, which is by no means an easy thing to do. However, Autor, Levy, and Murnane (2003) have shown that it is possible to distinguish the tasks performed in a country using data on the distribution of workers across occupations and information about the type of work performed by individuals in each narrowly defined occupational category. They have measured the specialization of the U.S. economy across five task categories: routine and manual, routine and cognitive, nonroutine and interactive, nonroutine and analytic, and nonroutine and manual. Since the 1980's, the United States has been specializing more in tasks that are nonroutine and either interactive or analytic, and less in the other three categories of tasks.

Spitz-Oener (2006) has conducted a similar exercise using German data. She found that the pattern of specialization across tasks has evolved similarly in Germany as in the United States, except that Germany is performing more tasks that are nonroutine and manual over time, unlike the United States. The evidence supports the plausible conclusion that routine tasks are migrating to low-income countries like China, India, and Mexico, with the high-income countries specializing increasingly in the set of nonroutine tasks. But the evidence also suggests that Germany is specializing in a different set of nonroutine tasks than the United States, namely, those that are more manual in nature. Given that Germany is smaller than the United States in terms of aggregate output and it has lower wages, our theory predicts that it should specialize in tasks that are relatively easier to offshore. Our prediction accords with the available evidence to the extent that (nonroutine) manual tasks can more readily be organized and coordinated from a distance than interactive or analytic tasks. This ranking of relative offshoring costs seems plausible to us, but we could find no direct evidence to confirm it.

Ideally, empirical research on task trade would begin by classifying tasks according to the relative ease of offshoring. More data on offshoring are becoming available as awareness of this phenomenon grows, so it may soon be 
possible to measure the offshoring costs for different tasks. Once that is possible, it will also be possible to study the pattern of specialization by task. We hope that our theory can help guide such efforts.

\section{APPENDIX}

In this Appendix, we prove Propositions 3, 4, 5, and 7.

Proof of Proposition 3: Equations (1), (3), and (2) define thresholds $I$, $I^{*}$, and $J$ as continuous functions of the two triplets $(n, x, w)$ and $\left(n^{*}, x^{*}, w^{*}\right)$. For values of $w$ such that $w \neq w^{*}$, Proposition 1 uses these thresholds to determine uniquely the three sets $\{\mathcal{E}, \mathcal{W}, \mathcal{D}\}$ as functions of $(n, x, w)$ and $\left(n^{*}, x^{*}, w^{*}\right)$. Furthermore, $M(\mathcal{Z})$ and $T(\mathcal{Z})$ for $\mathcal{Z}=\{\mathcal{E}, \mathcal{W}, \mathcal{D}\}$ are continuous functions of the set of thresholds $\left(I, I^{*}, J\right)$ by the theorem of the maximum. We can then use the eight equations (5)-(11) plus (13) to solve for $n, n^{*}, x, x^{*}$, $s, s^{*}, c$, and $c^{*}$ as functions of the wage in East $w$, after normalizing $w^{*}=1$. Substituting these solutions into what results from dividing equation (12) by (13) yields an expression of the form $\Theta\left(w ; L, L^{*}\right)=L / L^{*}$, where $\Theta\left(w ; L, L^{*}\right)$ denotes the relative quantity of labor demanded in East as a function of the relative wage (given endowments). To show existence, we need to guarantee that there exists a value of $w$ (including, possibly, $w=1$ ) such that this equation is satisfied. Given that all expressions in the eight equations (5)-(11) plus (13) are continuous in all variables, $\Theta\left(w ; L, L^{*}\right)$ is continuous as long as $w \neq 1$.

For $w=1$, the task allocation is not pinned down by Proposition 1 . In this case, it must be that $n x=n^{*} x^{*}$, because otherwise all tasks would be performed in the same country, which is inconsistent with equations (5)-(11). If, in fact, $n x=n^{*} x^{*}$ and $w=1$, then any specialized task can be concentrated in either country without being subject to a local or global deviation. Hence $I=I^{*}$, but the location of tasks in $[0, I]$ is not determined. Any division of these tasks between countries that satisfies (5)-(11) plus (13) is possible in equilibrium, and the particular division determines some possible value of $\Theta(1) .{ }^{26}$ Consequently, $\Theta(1)$ is potentially an interval and $\Theta(w)$ is potentially a correspondence, since when $w=1$, a division of tasks can always replicate the allocation dictated by Proposition 1 for $w \gtrsim 1$ or $w \lesssim 1$ (sufficiently close but not equal to 1$), \lim _{w \searrow 1} \Theta(w) \in \Theta(1)$ and $\lim _{w>1} \Theta(w) \in \Theta(1)$. Note also that if $\lim _{w \searrow 1} \Theta(w) \neq \lim _{w>1} \Theta(w)$, then any value between these two limits is also an element of $\Theta(1)$, since we can choose $\{\mathcal{E}, \mathcal{W}\}$ arbitrarily as long as $M(\mathcal{E})+M(\mathcal{W})=I$. If $I=I^{*}=0$, so that $\mathcal{E}=\mathcal{W}=\emptyset$, then $\lim _{w \searrow 1} \Theta(w)=\lim _{w \nearrow 1} \Theta(w)$ and so $\Theta(1)$ must be a singleton. Hence $\Theta(w)$ is a compact-valued and upper-hemicontinuous correspondence that is singlevalued except possibly for $w=1$.

\footnotetext{
${ }^{26}$ We henceforth abbreviate $\Theta\left(w ; L, L^{*}\right)$ by $\Theta(w)$, while reminding the reader that the location of this relative demand curve always depends on the two factor endowments, inasmuch as the factor endowments directly determine $n$ and $n^{*}$ via (10) and (11).
} 
(a)

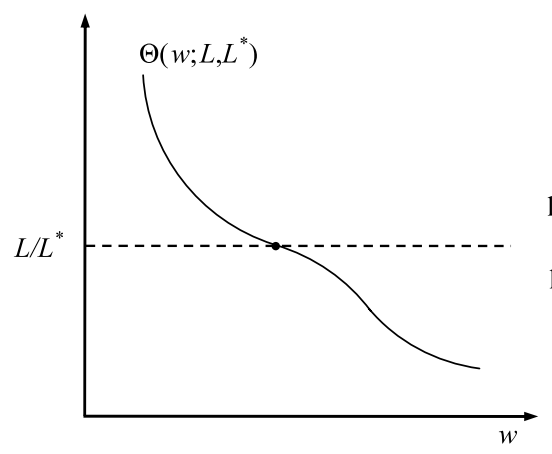

(b)

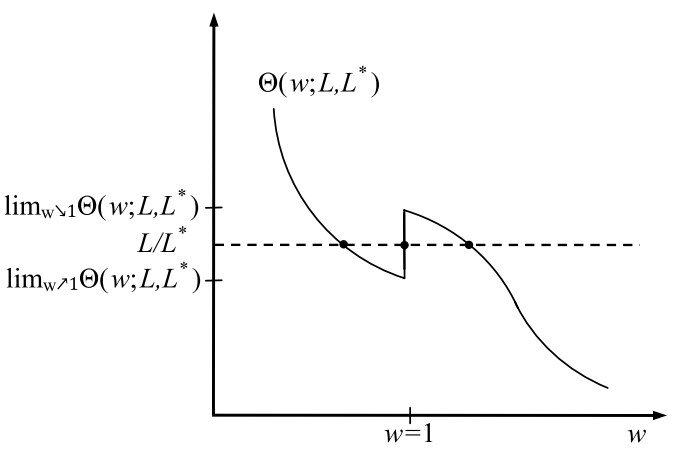

FIGURE A1.-Existence of general equilibrium.

Clearly, $\lim _{w \rightarrow \infty} \Theta(w)=0$ for all $L$ and $L^{*}$, since $\lim _{w \rightarrow \infty} I \rightarrow 0$ and $\lim _{w \rightarrow \infty} I^{*} \rightarrow 1$ so that, in the limit, $\mathcal{E}$ and $\mathcal{D}$ are empty. Also, $\lim _{w \rightarrow 0} \Theta(w)=\infty$ for all $L$ and $L^{*}$, since in that case, $\lim _{w \rightarrow 0} I^{*} \rightarrow 0$ and $\lim _{w \rightarrow 0} I \rightarrow 1$, and so $\lim _{w \rightarrow 0} \mathcal{E}=[0,1]$, which implies that the left-hand side of (13) converges to zero and so $\lim _{w \rightarrow 0} \Theta(w)=\infty$. The intermediate value theorem as applied to upper-hemicontinuous correspondences then guarantees that there exists a $w$ such that $L / L^{*} \in \Theta\left(w ; L, L^{*}\right)$.

An example of an upper-hemicontinuous correspondence with these features, and the associated equilibria, are presented in Figure A1. Panel (a) illustrates a case in which $\mathcal{E}=\mathcal{W}=\emptyset$ so that $\Theta(1)$ is a singleton and $\Theta(w)$ is continuous; panel (b) illustrates a case in which $\Theta(1)$ is an interval and so multiple equilibria exist. The proof of Proposition 4 characterizes this case further.

Q.E.D.

Proof of Proposition 4: Proposition 3 guarantees the existence of an equilibrium; the rest of the proposition is proven in parts.

Part (i)(a). We first show that if $H=H^{*}$ and $\beta$ is high enough, a symmetric equilibrium exists. We then show that this equilibrium is unique. Since $H=H^{*}$, equations (10) and (11) imply that $n=n^{*}$. Now consider a symmetric equilibrium with $x=x^{*}$ and $w=1$. Then equations (1) and (3) imply that $I=I^{*}$. Furthermore, the concavity of $A$ implies that $A(2 n x)<2 A(n x)$ and so $\beta t(I)<2$. Let $\beta_{\mathrm{NO}}=2 / t(0)$. Since $t(\cdot)$ is an increasing function, this implies that for any $\beta>\beta_{\mathrm{NO}}, I=I^{*}=0$. So if $\beta>\beta_{\mathrm{NO}}$, we obtain that $\mathcal{E}, \mathcal{W}=\emptyset$ and $\mathcal{D}=[0,1]$. This implies that the labor market clearing conditions (12) and (13) are given by $\Psi(n x) \equiv n x / A(n x)=L=L^{*}$. This equation is guaranteed to have a unique solution with positive output since $A(0)>0, A(\cdot)$ is increasing and concave, and $\lim _{n x \rightarrow \infty} A^{\prime}(n x)=0$, so $\Psi(\cdot)$ is a monotonically increasing function with $\Psi(0)=0$ and $\lim _{n x \rightarrow \infty} \Psi(n x)=\infty$. Equations (5) and (6) then imply that $c=c^{*}=1 / A(n x)$. Hence in this case, there exists a unique symmetric equilibrium. 
To show, by contradiction, that this symmetric equilibrium is the unique equilibrium of this economy for $\beta$ sufficiently high, suppose there exists an asymmetric equilibrium. Now suppose that for any $\beta$, the asymmetric equilibrium exhibits $\mathcal{E}$ and $\mathcal{W}$ such that $M(\mathcal{E})>0$ and $M(\mathcal{W})>0$. Then $\lim _{\beta \rightarrow \infty} T(\mathcal{E})=\lim _{\beta \rightarrow \infty} T(\mathcal{W})=\infty$. But then equations (12) and (13) can only be satisfied for $x=x^{*}=0$, which contradicts our assumption that we are in an asymmetric equilibrium. Hence, there exists a $\beta$ high enough such that $M(\mathcal{E})=M(\mathcal{W})=0$. Consider a value of $\beta$ such that this is the case. Then equations (12) and (13) imply that $\Psi(n x)=L$ and $\Psi\left(n x^{*}\right)=L$, which given the assumption on $A(\cdot)$, implies that $x=x^{*}$ - a contradiction with our assumption that the equilibrium is asymmetric. Hence, there exists a high enough $\beta$ such that the unique equilibrium of this economy is symmetric and exhibits no offshoring.

Part (i)(b). Fix $\beta>\beta_{\mathrm{NO}}$ and suppose that $L / L^{*}$ is such that $M(\mathcal{E})=$ $M(\mathcal{W})=0$. We show below that such an equilibrium exists and is unique. Combining equations (5)-(13) we obtain that the equilibrium is implicitly determined by three equations, namely $L=\Psi(n x), L^{*}=\Psi\left(n^{*} x^{*}\right)$, and $x / x^{*}=$ $w^{\sigma /(\sigma-1)}$, where $n=H / f$ and $n^{*}=H^{*} / f$. As for part (i)(a), given $L$ and $H$, the first equation gives a unique solution for $x$, the second for $x^{*}$, and, therefore, the third for $w$. Now $n x=\Psi^{-1}(L)$, so for $w$ to be increasing in $L$, given $L^{*}$ and $L / H=L^{*} / H^{*}$, we need $\Psi^{-1}(L) / L$ to be an increasing function. Now

$$
\frac{d\left[\frac{\Psi^{-1}(L)}{L}\right]}{d L}=\frac{1}{L^{2} \Psi^{\prime}(n x)}\left[L-L+\frac{n x}{A^{2}(n x)} A^{\prime}(n x)\right]>0 .
$$

For this allocation to be the unique equilibrium, we still have to verify that there exists an $\ell_{H}>1$ such that $L / L^{*}<\ell_{H}$, the resulting $n x$ and $n^{*} x^{*}$ imply that $I=I^{*}=0$, and so $M(\mathcal{E})=M(\mathcal{W})=0$. Since $\beta>\beta_{\mathrm{NO}}$, then $\beta t(0)>2$. But note that as $L / L^{*} \rightarrow \infty$, the equilibrium above implies that $n x / n^{*} x^{*} \rightarrow 1$ and $w \rightarrow 1$, and so in the limit $I=I^{*}=0$. Hence there exists some $\ell_{H}>1$ such that $L / L^{*}<\ell_{H}$ implies that $\frac{A\left(n x+n^{*} x^{*}\right)}{w A\left(n^{*} x^{*}\right)}<2$ and $\frac{w A\left(n x+n^{*} x^{*}\right)}{A(n x)}<2$, and so $I=I^{*}=0$.

Part (ii). We now show that if $L / L^{*}$ is large enough, then the equilibrium exhibits $n x>n^{*} x^{*}$ and $w>1$ for any $\beta$. Take the limit as $L / L^{*} \rightarrow \infty$. Toward a contradiction, assume that $w<1$ and so $n^{*} x^{*}>n x$. Then by equations (10) and (11), $n / n^{*} \rightarrow \infty$ and so it must be that $x / x^{*} \rightarrow 0$. But this requires $c / c^{*} \rightarrow \infty$. Note that by (5) and (6),

$$
\frac{c}{c^{*}}=\frac{w M(\mathcal{E})+T(\mathcal{W})+w M(\mathcal{D}) \frac{A\left(n x+n^{*} x^{*}\right)}{A(n x)}}{w T(\mathcal{E})+M(\mathcal{W})+M(\mathcal{D}) \frac{A\left(n x+n^{*} x^{*}\right)}{A\left(n^{*} x^{*}\right)}},
$$


which is bounded unless $n^{*} x^{*} / n x \rightarrow \infty$ and $M(\mathcal{D})>0$. Suppose that is the case. Then

$$
\begin{aligned}
& \quad \lim _{\left(n^{*} x^{*}\right) /(n x) \rightarrow \infty} \frac{M(\mathcal{E})+T(\mathcal{E}) \frac{n^{*} x^{*}}{n x}+M(\mathcal{D}) \frac{A\left(n x+n^{*} x^{*}\right)}{A(n x)}}{T(\mathcal{W})+M(\mathcal{W}) \frac{n^{*} x^{*}}{n x}+M(\mathcal{D}) \frac{A\left(n x+n^{*} x^{*}\right)}{A\left(n^{*} x^{*}\right)} \frac{n^{*} x^{*}}{n x}} \\
& \leq \lim _{\left(n^{*} x^{*}\right) /(n x) \rightarrow \infty} \frac{T(\mathcal{E})+M(\mathcal{D})}{M(\mathcal{W})+M(\mathcal{D})}<\infty,
\end{aligned}
$$

since $M(\mathcal{D})>0$, which implies that $I<1$ and so $T(\mathcal{E})<M(\mathcal{E}) \beta t(I)<\infty-$ a contradiction with $L / L^{*} \rightarrow \infty$, and (12) and (13).

Q.E.D.

Proof of Proposition 5: For any values of $L$ and $L^{*}$, Proposition 3 and Lemma 3 ensure that an equilibrium exists and that whenever $w \neq 1$, either $w>1$ and $n x>n^{*} x^{*}$ or $w<1$ and $n x<n^{*} x^{*}$. Here we prove that there exists a finite $\ell_{L}$ such that an equilibrium with $w=1$ and $n x=n^{*} x^{*}$ exists if $\ell_{L}>$ $L / L^{*}>1 / \ell_{L}$ and does not exist if $L / L^{*}>\ell_{L}$ or $L / L^{*}<1 / \ell_{L}$. We then show that if an equilibrium with $w=1$ exists for some factor endowments, then, generically, equilibria with $w>1$ and with $w<1$ also exist for these same factor endowments. The proof of the remainder of part (ii) is identical to the proof of part (ii) in Proposition 4.

For $\beta$ low enough and $H / H^{*}=L / L^{*}=1$, the existence of an equilibrium with $w=1$ and $n x=n^{*} x^{*}$ is immediate, because $I=I^{*}$ in such circumstances, and we can let $M(\mathcal{E})=M(\mathcal{W})$ and $T(\mathcal{E})=T(\mathcal{W})$. The low value of $\beta$ guarantees that $M(\mathcal{E})=M(\mathcal{W})>0$. This implies, using the notation for the relative demand for labor defined in the proof of Proposition 3, that $\Theta(1)=1=L / L^{*} .^{27}$

Now consider the possible existence of an equal-wage equilibrium for $L / L^{*}>1$. If $w=1$ and $n x=n^{*} x^{*}$, we still have by equations (1) and (3) that $I=I^{*}$, and so we are free to choose $\mathcal{E}$ and $\mathcal{W}$ in any way so as to satisfy the remaining equilibrium conditions. In particular, we need to choose $\mathcal{E}$ and $\mathcal{W}$ so as to satisfy (12), (13), (5), (6), and (7). Together with $1-M(\mathcal{D})=$ $M(\mathcal{E})+M(\mathcal{W}), \int_{0}^{1-M(\mathcal{D})} \beta t(i) d i=T(\mathcal{E})+T(\mathcal{W})$, and $\beta t(1-M(\mathcal{D}))=$ $A(2 n x) / A(n x)$, we arrive at a system of six equations in six unknowns. There exists an $\ell_{L}>1$ such that this system of equations has a unique solution for $\ell_{L}>L / L^{*}>1 / \ell_{L}$. On the other hand, for $L / L^{*}$ sufficiently large, there can be no solution, because $T(\mathcal{W})<M(\mathcal{W}) \beta t(I)<2 M(\mathcal{W})$ and so (5), (6), and (7) imply that

$$
2>\frac{1+T(\mathcal{W})-M(\mathcal{W})}{1+T(\mathcal{E})-M(\mathcal{E})}>\left(\frac{L}{L^{*}}\right)^{1 / \sigma} .
$$

\footnotetext{
${ }^{27}$ Again, we write the relative labor demand as $\Theta(w)$, while stressing that this function depends on $L$ and $L^{*}$, as well as on all of the other parameters.
} 
It follows that an equal-wage equilibrium cannot exist for $L / L^{*}>2^{\sigma}$. Hence, there exists a $2^{\sigma} \geq \ell_{L}>1$ such that an equal-wage equilibrium exists for $\ell_{L}>$ $L / L^{*} \geq 1$ and an equal-wage equilibrium does not exist for $L / L^{*}>\ell_{L}$. The case for $L / L^{*}<1$ is analogous and yields the result that a set of equal-wage equilibria exists as long as $L / L^{*}>1 / \ell$.

It remains to show that if $\beta<\beta_{\mathrm{NO}}$ and $L / L^{*}$ is such that a set of equal-wage equilibria exists, then generically there also exist two other equilibria: one with $w>1$ and another with $w<1$. Note that when $\beta<\beta_{\mathrm{NO}}$ and $w=1, \mathcal{E}$ and $\mathcal{W}$ are not empty, which implies that $\lim _{w \backslash 1} \Theta(w) \neq \lim _{w \succ 1} \Theta(w)$. To prove the result, it is sufficient to show that in such circumstances, $\lim _{w \backslash 1} \Theta(w) \geq$ $\lim _{w \succ 1} \Theta(w)$, as depicted in panel (b) of Figure A1. If this is so, the fact that $L / L^{*} \in \Theta(1)$ and $\min \Theta(1) \leq L / L^{*} \leq \max \Theta(1)$ implies that there exists a $w<1$ such that $\Theta(w)=L / L^{*}$. This conclusion follows by application of the intermediate value theorem after recalling from the proof of Proposition 3 that $\lim _{w \backslash 1} \Theta(w) \in \Theta(1), \Theta(w)$ is continuous for all $w<1$, and $\lim _{w \rightarrow 0} \Theta(w)=\infty$. A similar argument guarantees that an equilibrium with $w>1$ exists as well. Panel (b) of Figure A1 shows the three possible equilibrium values for $w{ }^{28}$

We now show that $\lim _{w \backslash 1} \Theta(w) \geq \lim _{w>1} \Theta(w)$. The existence of an equalwage equilibrium implies $L / L^{*} \in \Theta(1)$. In such an equilibrium, $n x=n^{*} x^{*}$ and $T(\mathcal{E}) \leq T([0, I])-T([0, M(\mathcal{W})])$. When $w \gtrsim 1$, Proposition 1 prescribes an allocation of tasks to countries such that $\mathcal{E}=[M(\mathcal{W}), I]$ and, therefore, $T(\mathcal{E})=T([0, I])-T([0, M(\mathcal{W})])$. Since the ratio of (12) and (13) evaluated at $w=1$ and $n x=n^{*} x^{*}$ is increasing in $T(\mathcal{E})$ and decreasing in $T(\mathcal{W})$, we conclude that $\lim _{w \backslash 1} \Theta(w) \geq L / L^{*}$. A similar argument guarantees that $L / L^{*} \geq \lim _{w>1} \Theta(w)$. Hence $\lim _{w \backslash 1} \Theta(w) \geq \lim _{w \nearrow 1} \Theta(w)$.

Q.E.D.

Proof of Proposition 7: When $H>H^{*}$ and $\beta$ is sufficiently large, the proof of Proposition 4 shows that the unique equilibrium is such that $w>w^{*}=$ 1 where $w$ increases with $H / H^{*}$. Divide equations (1) and (3) and use (12), (13), and $H / L=H^{*} / L^{*}$ to obtain $t(I) / t\left(I^{*}\right)=x /\left(x w^{2}\right)$ when $M(\mathcal{E})=0$ and $M(\mathcal{W})=0$. Substituting $x / x^{*}=w^{\sigma /(\sigma-1)}$ (see the proof of Proposition 4), we obtain that $t(I) / t\left(I^{*}\right)=w^{(2-\sigma) /(\sigma-1)}$. Since $w>1$, this equation can only be satisfied for $I=I^{*}$ when $\sigma=2$. Hence, for $\sigma=2$, (1) and (3) are such that

$$
I=t^{-1}\left(\frac{1}{\beta} \frac{1}{w} \frac{A\left(n x+n^{*} x^{*}\right)}{A\left(n^{*} x^{*}\right)}\right)=0=t^{-1}\left(\frac{1}{\beta} w \frac{A\left(n x+n^{*} x^{*}\right)}{A(n x)}\right)=I^{*}
$$

and so both countries start offshoring for the same value of $H / H^{*}$. When $\sigma>2,(I) / t\left(I^{*}\right)=w^{(2-\sigma) /(\sigma-1)}$ implies that $t(I)<t\left(I^{*}\right)$, and since $t(\cdot)$ is an

\footnotetext{
${ }^{28}$ Note that if $L / L^{*}=\min \Theta(1)$, then the argument only guarantees that an equilibrium with $w>1$ exists, while if $L / L^{*}=\max \Theta(1)$, it guarantees that an equilibrium with $w<1$ exists. These cases arise only for sets of measure zero in the parameter space, and in either of these cases, there exist at least two equilibrium values of $w$.
} 
increasing function, we conclude that $0=I>I^{*}$, which implies that East offshores first as we increase $H$. If $\sigma<2$, then $t(I)>t\left(I^{*}\right)$ and so $0=I^{*}>I$, which implies that West offshores first as we increase $H$.

Q.E.D.

\section{REFERENCES}

Autor, D., F. Levy, AND R. Murnane (2003): "The Skill Content of Recent Technological Change: An Empirical Exploration," Quarterly Journal of Economics, 118, 1279-1333. [595,622]

BALDWIN, R. E., AND F. ROBERT-NICOUD (2010): "Trade-in-Goods and Trade-in-Tasks: An Integrating Framework,” Working Paper 15882, NBER. [593]

BAREFOOT, K. B., AND R. J. MATALONI, JR. (2010): "US Multinational Corporations: Operations in the United States and Abroad in 2008," Survey of Current Business, 90, 205-230. [594]

CAMPA, J. M., AND L. S. GOLDBERG (1997): "The Evolving External Orientation of Manufacturing Industries: Evidence From Four Countries," FRB of NY Economic Policy Review, 3, 53-81. [594]

DEARDorfF, A. V. (2001): "Fragmentation in Simple Trade Models," North American Journal of Economics and Finance, 12, 121-137. [593]

EGGER, H., AND J. FALKINGER (2003): "The Distributional Effects of International Outsourcing in a $2 \times 2$ Model," North American Journal of Economics and Finance, 14, 189-206. [593]

ETHIER, W. J. (1982): "Decreasing Costs in International Trade and Frank Graham's Argument for Protection," Econometrica, 50, 1243-1268. [597]

FEENSTRA, R. C., AND G. H. HANSON (1996): "Foreign Investment, Outsourcing and Relative Wages," in The Political Economy of Trade Policy: Papers in Honor of Jagdish Bhagwati, ed. by R. C. Feenstra, G. M. Grossman, and D. A. Irwin. Cambridge: MIT Press. [593]

Grossman, G. M., AND E. Rossi-HANSBERG (2008): "Trading Tasks: A Simple Theory of Offshoring," American Economic Review, 98, 1978-1997. [593,595,599]

(2010): "External Economies and International Trade Redux," Quarterly Journal of Economics, 125, 829-858. [596,597]

(2012), "Supplement to 'Task Trude Between Similar Countries'," in Econometrica Supplemental Material, 80, http://www.econometricsociety.org/ecta/Supmat/8700_Proofs.pdf. [602,606]

HANSON, G. H., AND C. XIANG (2004): “The Home-Market Effect and Bilateral Trade Patterns,” American Economic Review, 94, 1108-1129. [597]

HANSON, G. H., R. J. Mataloni, JR., AND M. J. Slaughter (2005): "Vertical Production Networks in Multinational Firms," Review of Economics and Statistics, 87, 664-678. [594]

HELPMAN, E. (1984): "Increasing Returns, Imperfect Markets, and Trade Theory," in Handbook of International Economics, ed. by R. Jones and P. Kenen. New York: Elsevier. [597,598]

HuMmels, D., J. IsHII, AND K.-M. YI (2001): "The Nature and Growth of Vertical Specialization in World Trade," Journal of International Economics, 54, 75-96. [594]

HumMEls, D., D. RAPOPORT, AND K.-M. YI (1998): "Vertical Specialization and the Changing Nature of World Trade," FRB of NY Economic Policy Review, 4, 79-99. [594]

JONES, R. W., AND H. KIERZKOWSKI (2001): "Globalization and the Consequences of International Fragmentation," in Money, Capital Mobility and Trade: Essays in Honor of Robert A. Mundell, ed. by R. Dornbusch. Cambridge: MIT Press. [593]

KOHLER, W. (2004a): "Aspects of International Fragmentation," Review of International Economics, 12, 793-816. [593]

(2004b): "International Outsourcing and Factor Prices With Multistage Production," Economic Journal, 114, C166-C185. [593]

KrugMan, P. R. (1979): "Increasing Returns, Monopolistic Competition, and International trade," Journal of International Economics, 9, 469-479. [615]

(1980): "Scale Economies, Product Differentiation, and the Pattern of Trade," American Economic Review, 70, 950-959. [597] 
Levy, F., AND R. Murnane (2004): The New Division of Labor. Princeton: Princeton University Press. [595]

LUCAS, R. E. (2002): Lectures on Economic Growth. Cambridge: Harvard University Press. [598] MARKusen, J. R., AND J. R. MElvin (1981): "Trade, Factor Prices, and the Gains From Trade With Increasing Returns to Scale," Canadian Journal of Economics, 14, 450-469. [597]

MARSHALL, A. (1920): Principles of Economics. London: Macmillan. [598]

MELVIN, J. R. (1969): “Increasing Returns to Scale as a Determinant of Trade," Canadian Journal of Economics, 2, 389-402. [597]

NEWHOUSE, J. (2007): Boeing versus Airbus: The Inside Story of the Greatest International Competition in Business. New York: A. A. Knopf. [594]

Romer, P. M. (1986): "Increasing Returns and Long-Run Growth,” Journal of Political Economy, 94, 1002-1037. [598]

SPITZ-OEnER, A. (2006): "Technical Change, Job Tasks, and Rising Educational Demands: Looking outside the Wage Structure," Journal of Labor Economics, 24, 235-270. [622]

World Trade Organization and IDE-JETRO (2011): Trade Patterns and Global Value Chains in East Asia: From Trade in Goods to Trade in Tasks. Geneva: World Trade Organization. [594]

YI, K.-M. (2003): “Can Vertical Specialization Explain the Growth of World Trade?” Journal of Political Economy, 111, 52-102. [593]

Dept. of Economics, Princeton University, Princeton, NJ 08544-1021, U.S.A.; grossman@princeton.edu

and

Dept. of Economics, Princeton University, Princeton, NJ 08544-1021, U.S.A.; erossi@princeton.edu.

Manuscript received July, 2009; final revision received September, 2011. 